\title{
Actualizaciones en los métodos de monitorización cerebral regional en los pacientes neurocríticos: presión tisular de oxígeno, microdiálisis cerebral y técnicas de espectroscopía por infrarrojos
}

\author{
M.A. Poca*; J. Sahuquillo*; M.P. Mena; A. Vilalta y M. Riveiro** \\ Servicio de Neurocirugía* y Unidad de Cuidados Intensivos**. Unidad de Investigación de Neurotraumatología. Hospital Universitario Vall \\ d'Hebron. Universidad Autónoma de Barcelona. Barcelona
}

\section{Resumen}

El resultado final de los pacientes que han presentado un traumatismo craneoencefálico (TCE) depende de las lesiones primarias, pero también, y en gran medida, de las lesiones secundarias. El diagnóstico de un gran número de lesiones secundarias, y en especial de la isquemia cerebral, se centra en la monitorización simultánea de diversas variables encefálicas y sistémicas. En el momento actual, la monitorización continua de la presión intracraneal (PIC) se considera una medida indispensable en el manejo de los pacientes con un TCE grave que presentan cualquier tipo de lesión intracraneal. Sin embargo, la información que ofrece esta variable es insuficiente para diagnosticar los complejos procesos fisiopatológicos que caracterizan a las lesiones neurotraumáticas. Por ello, cada vez es más frecuente complementar la neuromonitorización de los pacientes con un TCE con métodos de estimación del flujo sanguíneo cerebral (FSC) como el Doppler transcraneal o las técnicas de oximetría yugular. Sin embargo, en el momento actual y en la cabecera del paciente, el conocimiento de la repercusión de las lesiones tisulares y de las medidas terapéuticas sobre el metabolismo cerebral requiere un acceso directo al parénquima encefálico. En esta revisión nos centraremos en tres métodos de monitorización cerebral "regional”: la presión tisular de oxígeno, la microdiálisis cerebral y las técnicas transcutáneas de espectroscopía por infrarrojos. En cada caso se expondrán los fundamentos del método en cuestión, los valores de referencia de los parámetros monitorizados y una serie de recomendaciones sobre cómo pueden interpretarse sus resultados a la luz de los conocimientos actuales.

PALABRAS CLAVE: Traumatismos craneoencefálicos. Metabolismo cerebral. Oxigenación tisular. Microdiálisis. Espectroscopía por infrarrojos.

Recibido: 20-01-05. Aceptado: 09-02-05
Recent advances in regional cerebral monitoring in the neurocritical patient: brain tissue oxygen pressure monitoring, cerebral microdialysis and near-infrared spectroscopy

Summary

The long term outcome of head-injured patients depends not only on the primary brain lesions but also to a large extent on the secondary lesions. The diagnosis of many secondary lesions, and specially that of brain ischemia, is based on simultaneous monitoring of several intracranial and systemic variables. Continuous intracranial pressure (ICP) monitoring is currently considered indispensable in the management of all patients with a severe head injury and intracranial lesions. However, the information provided by this technique is insufficient to diagnose some of the complex physiopathological processes that characterize traumatic brain lesions. Consequently, the use of methods to estimate cerebral blood flow such as transcranial Doppler and jugular oximetry to complement ICP monitoring is becoming increasingly widespread. Nevertheless, determining the effect of tissue lesions and therapeutic measures on cerebral metabolism currently requires direct access to the brain parenchyma at the bedside. In this review we focus on three methods of regional cerebral monitoring: oxygen tissue pressure $\left(\mathrm{PtiO}_{2}\right)$ monitoring, microdialysis and near-infrared spectroscopy. The bases of each method and reference values for the varia-

Abreviaturas. $\mathrm{CEO}_{2}$ : extracción cerebral de oxígeno. FSC: flujo sanguíneo cerebral. Hb: hemoglobina. LCR: líquido cefalorraquideo. $\mathrm{O}_{2}$ : oxígeno. $\mathrm{PaO}_{2}$ : presión arterial de oxígeno. $\mathrm{PaCO}_{2}$ : presión arterial de dióxido de carbono. PIC: presión intracraneal. PPC: presión de perfusión cerebral. $\mathrm{PtiO}_{2}$ : presión tisular de oxígeno. $\mathrm{SjO}_{2}$ : saturación en el bulbo de la yugular. SPECT: tomografía computarizada por emisión de positrones simple. TC: tomografía computarizada. TCDB: traumatic coma data bank. TCE: traumatismo craneoencefálico. UCI: unidad de cuidados intensivos 
bles analyzed will be discussed. We also make a series of recommendations on how results should be interpreted in light of current knowledge.

KEY WORDS: Head injury. Brain metabolism. Tissular oxygenation. Microdialysis. Near-infrared spectroscopy.

De la monitorización de la isquemia cerebral en los pacientes con un traumatismo craneoencefálico podemos decir:

- disponer de una información global nos orienta a un hecho,

- disponer de una información específica, regional o local, nos muestra un fenómeno puntual,

pero,

- disponer de una información combinada, global y regional, nos acerca de forma más precisa a una realidad.

\section{Introducción}

La hipoxia y/o la isquemia tisular son fenómenos frecuentes en los pacientes que han presentado un TCE grave. Variables como la presión de perfusión cerebral (PPC) y las técnicas de oximetría yugular ofrecen información indirecta sobre el FSC global. Otros parámetros hemometabólicos como el contenido de hemoglobina ( $\mathrm{Hb})$, la saturación arterial de oxígeno y la presión parcial de oxígeno $\left(\mathrm{PaO}_{2}\right)$ pueden añadir información sobre la disponibilidad de oxígeno $\left(\mathrm{O}_{2}\right)$ en los tejidos. Sin embargo, ninguna de estas medidas ofrece información directa sobre el grado de oxigenación ni sobre la situación metabólica del tejido cerebral.

Desde hace poco tiempo existe la posibilidad de medir la presión de $\mathrm{O}_{2}$ directamente en el parénquima encefálico. Esta nueva variable ofrece una información inmediata, continua y directa sobre el contenido tisular de $\mathrm{O}_{2}$. En estos últimos años las técnicas de microdiálisis también se han adaptado al estudio del metabolismo cerebral, permitiéndonos conocer a tiempo casi real los acontecimientos metabólicos que tienen lugar en el encéfalo de ciertos pacientes neurocríticos. Por último, sistemas no invasivos como la espectroscopía por infrarrojos nos permiten realizar estimaciones secuenciales del FSC de forma simple y en la cabecera del paciente. El objetivo último de estos nuevos sistemas de monitorización es detectar precozmente situaciones de hipoxia o isquemia tisular para poder corregirlas con un tratamiento adecuado.

En esta revisión pretendemos exponer los fundamentos, situación actual y diversos aspectos prácticos relacionados con los tres sistemas regionales más utilizados en el momento actual, para complementar la neuromonitorización que podemos aplicar a los pacientes neurocríticos: la monitorización de la presión tisular de $\mathrm{O}_{2}$, la microdiálisis cerebral y las técnicas transcutáneas de espectroscopía por infrarrojos.

\section{MONITORIZACIÓN INVASIVA DE LA OXIGENACIÓN CERE- BRAL}

\section{Presión tisular de oxígeno en el cerebro}

La cuantificación de la presión tisular de oxígeno $\left(\mathrm{PtiO}_{2}\right)$ en el cerebro se realiza a partir de la introducción en el parénquima encefálico de un catéter de pequeño calibre y sensible al $\mathrm{O}_{2}$. A pesar de que en el tejido metabólicamente activo existen gradientes en la concentración de $\mathrm{O}_{2}$ entre los compartimentos vascular, extra e intracelular ${ }^{92}$, se asume que los sensores de $\mathrm{PtiO}_{2}$ proporcionan valores promedio de las concentraciones de $\mathrm{O}_{2}$ de todos estos compartimentos, y que su lectura final corresponde a la presión parcial de $\mathrm{O}_{2}$ al final del circuito capilar ${ }^{48}$. Otro concepto asumido es que la $\mathrm{PtiO}_{2}$ refleja el balance entre el aporte y el consumo de $\mathrm{O}_{2}$ a nivel celular, lo que condiciona que, frente a una situación de isquemia tisular, los valores de $\mathrm{PtiO}_{2}$ sean inferiores a los normales ${ }^{48}$. Zauner y col. ${ }^{103}$ objetivaron que en situaciones de isquemia tisular el descenso de la $\mathrm{PtiO}_{2}$ se acompañaba de una disminución del $\mathrm{pH}$ y de un aumento de la presión tisular de $\mathrm{CO}_{2}$, dada la falta de intercambio metabólico entre las células y el circuito capilar.

Diversos estudios in vitro e in vivo han demostrado la fiabilidad de la $\mathrm{PtiO}_{2}$, al comparar sus valores con un "patrón oro" "24,56. En el ámbito clínico, la monitorización multimodal aplicada a los pacientes neurocríticos ha objetivado que la $\mathrm{PtiO}_{2}$ es un parámetro extremadamente sensible, cuya información precede a la que ofrecen otros sistemas de monitorización (Fig. 1). Valores bajos de la $\mathrm{PtiO}_{2}$ indican que existe una hipoxia tisular y pueden ayudarnos a individualizar las maniobras terapéuticas y a valorar su efectividad. Debemos recordar que la disponibilidad real de $\mathrm{O}_{2}$ en un tejido, además de depender de la presión parcial de $\mathrm{O}_{2}$, depende del contenido hemático de hemoglobina, de la afinidad de la hemoglobina por el $\mathrm{O}_{2}$, del número de capilares funcionales, de la capacidad de difusión del $\mathrm{O}_{2}$ a través de las membranas celulares y de las características del espacio extracelular ${ }^{85}$.

\section{Origen de los sensores de oximetría tisular. Sistemas disponibles}

Los sensores de oximetría tisular no fueron ideados inicialmente para monitorizar el parénquima encefálico ${ }^{23,25}$. Contrastada y validada la información que ofrecían este tipo de sensores, su aplicación se dirigió inicialmente a la monitorización de órganos e injertos trasplantados, con el objetivo de evaluar su viabilidad. En el encéfalo, en un 


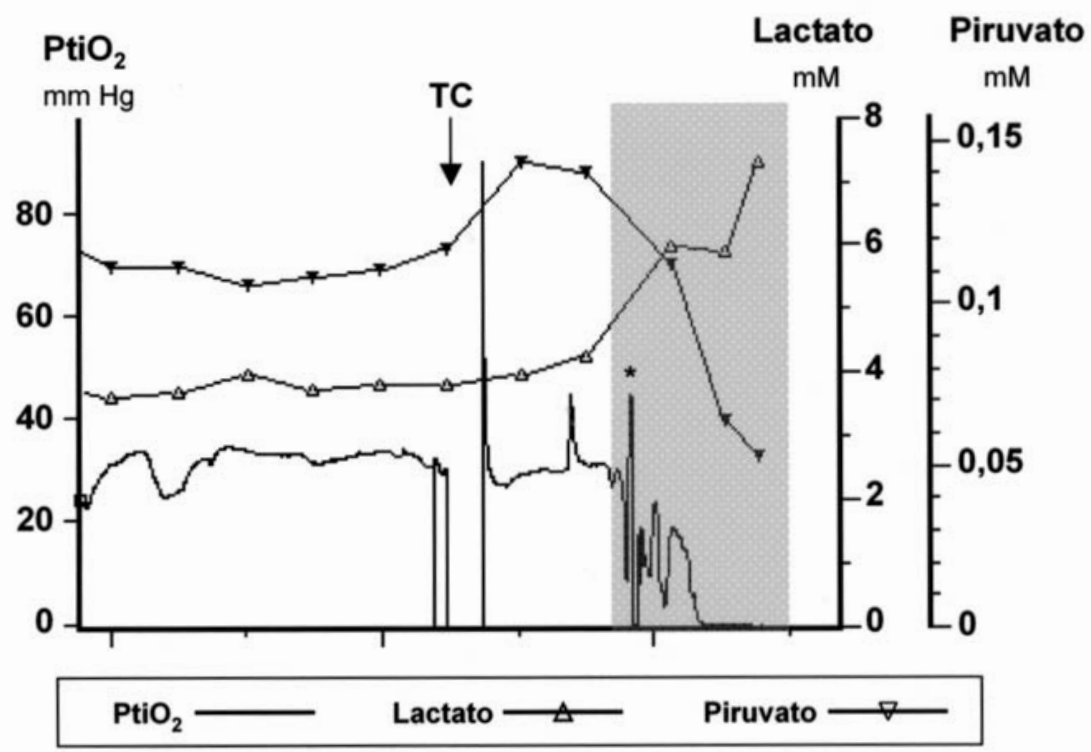

Figura 1. Efectividad de las maniobras de reanimación cardiaca sobre la PtiO (recuadro sombreado). La imagen muestra como de forma inmediata al masaje cardíaco la $\mathrm{PtiO}_{2}$ se eleva de forma transitoria. Finalmente, la reanimación no es efectiva y la PtiO ${ }_{2}$ cae definitivamente hasta $0 \mathrm{mmHg}$. Durante este periodo el lactato cerebral aumenta de forma importante y el piruvato disminuye, mostrando un patrón de isquemia cerebral irreversible.

primer periodo, se utilizaron para medir la presión de $\mathrm{O}_{2}$ en el líquido cefalorraquídeo (LCR ${ }^{24,56}$. Sin embargo, en el momento actual la medición continua de la $\mathrm{PtiO}_{2}$ complementa la neuromonitorización que aplicamos a un gran número de pacientes neurocríticos ${ }^{33,36,48}$. El sistema Licox es el método más utilizado y validado en el momento actual para medir la $\mathrm{PtiO}_{2}$. Por este motivo, en esta revisión nos referiremos de forma casi exclusiva a este sistema de monitorización.

El sistema Licox ${ }^{\circledR}$ (distribuido por GMS, Kiel-Milkendorf, Alemania) constituye el paradigma de los sensores de oximetría tisular. Este sistema utiliza una modificación de un electrodo polarográfico convencional de tipo Clark. En el ámbito clínico, algunos autores utilizan el sistema Neurotrend ${ }^{\circledR}$ como equipo alternativo -antiguo Paratrend(Multiparameter Intravascular Sensor, Biomedical Sensors, Malvern, PA), cuyo sensor permite la monitorización simultánea de varios parámetros a través de una única sonda $\left(\mathrm{O}_{2}\right.$, $\mathrm{CO}_{2}, \mathrm{pH}$ y temperatura). Sin embargo, Neurotrend es un sistema de reciente introducción y su fiabilidad todavía no está plenamente establecida. Su principal característica es que el método utilizado para monitorizar la presión parcial de $\mathrm{O}_{2}$ es colorimétrico y no polarográfico.

\section{Características técnicas del sistema Licox}

Los sensores Licox determinan la presión media de $\mathrm{O}_{2}$ tisular en una área de $14 \mathrm{~mm}^{2}$, promediando los valores de las presiones arteriolar, capilar, extracelular, intracelular y venosa. Implantándolos a cielo abierto en el quirófano, estos sensores pueden realizar mediciones de la $\mathrm{PtiO}_{2}$ en el córtex cerebral. Sin embargo, el sistema está especialmente diseñado para ser introducido en la sustancia blanca a través de un tornillo roscado (Fig. 2). El catéter se introduce unos $25 \mathrm{~mm}$ por debajo de la duramadre y queda ubicado en la sustancia blanca subcortical.

El extremo intracraneal del catéter se halla recubierto de una membrana de polietileno que permite una difusión libre de $\mathrm{O}_{2}$ desde el tejido al catéter. A unos 4-5 mm del extremo intracraneal del catéter se encuentra el "revoxode", que es donde tienen lugar las reacciones de óxido-reducción que permiten realizar la medición de la $\mathrm{PtiO}_{2}$. En su interior se encuentran un cátodo de oro y un ánodo de plata, inmersos en una solución electrolítica (Fig. 2). Las moléculas de $\mathrm{O}_{2}$ difunden hacia el interior del catéter, produciéndose una reacción reversible en el cátodo, en la que el $\mathrm{O}_{2}$ se combina con agua y se forman iones $\mathrm{OH}^{-}\left(\mathrm{O}_{2}+2 \mathrm{H}_{2} \mathrm{O}+4 \mathrm{e}^{-} \rightarrow\right.$ $\left.4 \mathrm{OH}^{-}\right)$. A partir de estas reacciones se genera una corriente eléctrica que será detectada por un voltímetro. La señal eléctrica se digitaliza y aparece trasformada en un valor numérico en el panel frontal del monitor.

\section{Valores "normales" de la $\mathrm{PtiO}_{2}$}

El rango de "normalidad" o de referencia para la $\mathrm{PtiO}_{2}$ en el cerebro no está todavía plenamente establecido. En general, se considera que los valores normales de la $\mathrm{PtiO}_{2}$ se sitúan entre los 15 y $30 \mathrm{mmHg}$, aunque algunos auto- 


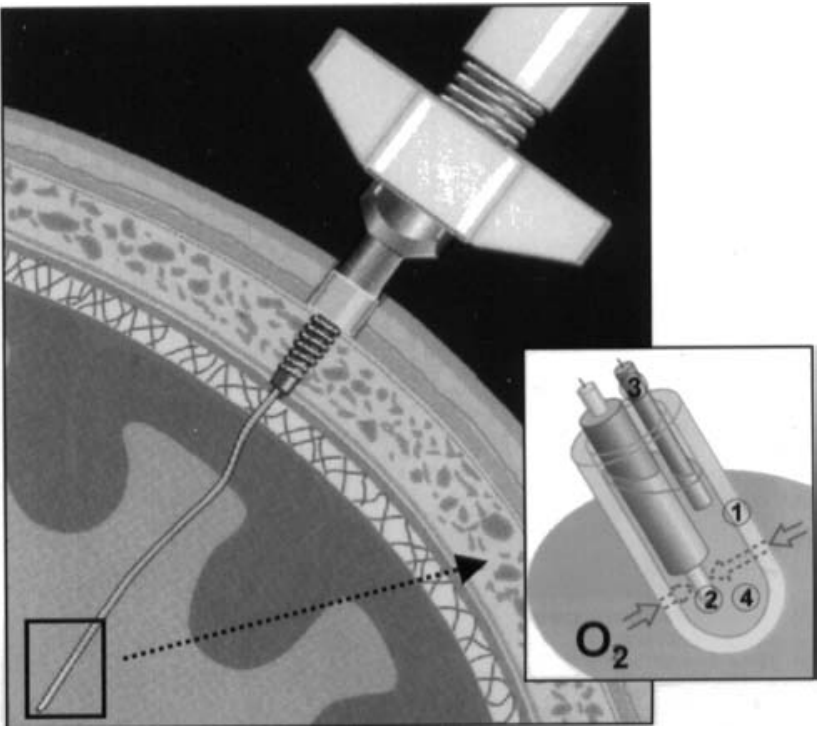

Figura 2. Esquema de un sensor de PtiO introducido en la cavidad craneal (modificación de una imagen cedida por $W$. Fleckenstein). El sensor se introduce en el cráneo a través de un tornillo roscado. El catéter se aloja en la sustancia blanca subcortical a unos $25 \mathrm{~mm}$ por debajo de la duramadre. En su extremo distal se localiza el "revoxode", que es donde van a tener lugar las reacciones de oxidación que generan la corriente eléctrica que determinará el valor de la $\mathrm{PtiO}_{2}$. 1: membrana permeable al $\mathrm{O}_{2}$; 2: cátodo de oro; 3: ánodo de plata; 4: solución hidroelectrolítica.

res afirman que en los TCE el rango superior debería ser más elevado. Valores de $\mathrm{PtiO}_{2}$ por debajo de $15 \mathrm{mmHg}$ indicarían la existencia de una hipoxia tisular ${ }^{36,48,81,97}$ que, según algunos autores, puede ser moderada (entre 15 y 10 $\mathrm{mmHg})^{49,97}$ o grave (por debajo de los $\left.10 \mathrm{mmHg}\right)^{47,51,81,97}$. De acuerdo con estos hallazgos y los de otros autores ${ }^{18}$, y en el contexto de los pacientes neurotraumáticos, uno de nuestros objetivos terapéuticos debería ser mantener cifras de $\mathrm{PtiO}_{2}$ por encima de los $20 \mathrm{mmHg}$.

La $\mathrm{PtiO}_{2}$ varía en función de la temperatura del tejido, a razón de aproximadamente un $4,4 \%$ por cada ${ }^{\circ} \mathrm{C}$ de cambio de temperatura ${ }^{100}$, lo que obliga a monitorizar de forma periódica o continua la temperatura del paciente. El monitor Licox permite monitorizar la temperatura cerebral de manera continua a través de un sensor específico, aunque este parámetro también puede introducirse de forma manual (Fig. 3). En nuestro centro habitualmente se utiliza un sistema manual, en el que la enfermera responsable del paciente introduce el valor de la temperatura cada hora. Dado que la temperatura cerebral es aproximadamente $1^{\circ} \mathrm{C}$ superior a la temperatura periférica, utilizamos el valor absoluto inmediatamente superior del valor de la temperatura central. De este modo, si el paciente presenta una temperatura esofágica o rectal de $36.5^{\circ} \mathrm{C}$, se introduce el

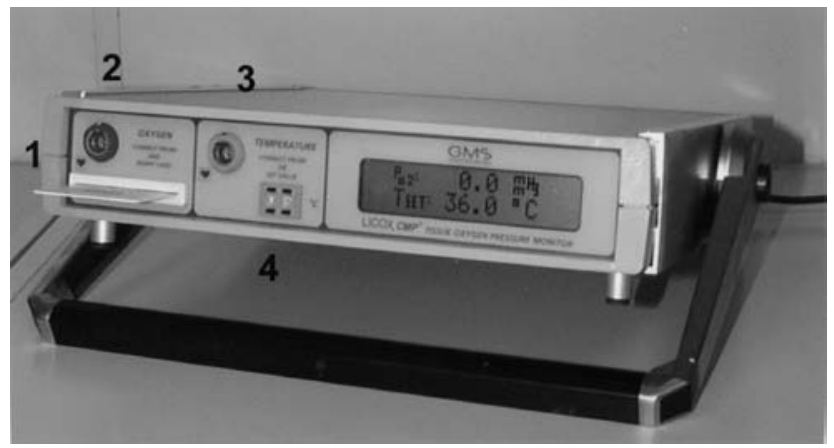

Figura 3. Esquema del panel frontal del monitor Licox. En la ranura de la derecha del monitor se introduce la tarjeta que contiene la información sobre la calibración de cada sensor (1). El monitor permite la conexión simultánea de un sensor de $\mathrm{PtiO}_{2}$ (2) y de un sensor de temperatura (3). El sensor de temperatura es opcional, aunque el monitor requiere esta variable de forma obligatoria para proporcionar valores fiables de $\mathrm{PtiO}_{2}$. Si no se utiliza un sensor de temperatura esta información debe introducirse de forma manual (4).

valor "37" en el monitor.

\section{Calibración e implantación de los catéteres}

Los sensores Licox no requieren una calibración previa a la implantación, dado que las calibraciones necesarias ya se han realizado durante su proceso de fabricación. Los sensores contienen una tarjeta específica dotada de un microchip. Cuando el monitor lo requiere, la tarjeta se introduce en la ranura correspondiente del monitor. A partir de este momento el monitor "reconoce" el sensor y dispone de los datos específicos de su calibración.

La colocación del sensor es muy simple y se asemeja, en gran medida, a la colocación de un sensor de PIC intraparenquimatoso. A través de una pequeña craneostomía, que puede realizarse en la misma unidad de cuidados intensivos (UCI), se fija un tornillo roscado en la calota craneal. El tornillo sujeta el introductor del sensor, cuya misión es realizar un pre-trayecto en el parénquima encefálico, lo que facilita el paso del fino catéter de oximetría y permite mantenerlo en una posición correcta (Fig. 4). En función del diámetro del tornillo (entre 3,0 y 5,3 mm) y del número de "luces" del introductor, a través de un único soporte pueden introducirse uno, dos o tres sensores (Fig. 4). Esta maniobra permite una monitorización multimodal ( $\mathrm{PtiO}_{2}$, temperatura, PIC o microdiálisis) con un mínimo riesgo para el paciente. Colocado el sensor, se introduce la tarjeta en la ranura del monitor y éste solicita de forma automática que se establezca la conexión entre el cable del monitor y el sensor.

A pesar de su pequeño diámetro $(0,5 \mathrm{~mm})$, el sensor se 


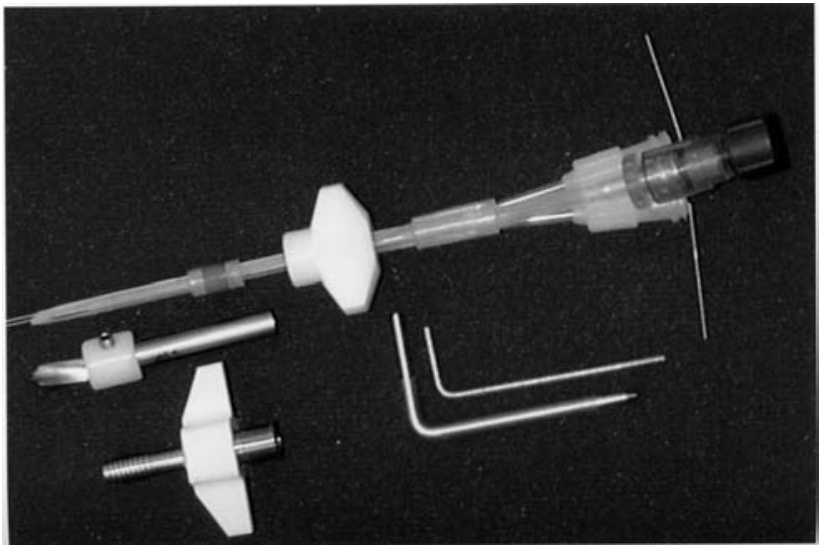

Figura 4. Tornillo e introductor de 3 vías que permite la monitorización simultánea de varios parámetros $\left(\mathrm{PtiO}_{2}\right.$, PIC, temperatura o microdiálisis).

identifica claramente en los controles radiológicos por TC, ofreciendo una imagen incluso más evidente que la de un sensor de PIC intraparenquimatoso (Fig. 5). La inserción del sensor supone una distorsión del parénquima encefálico ${ }^{98,102}$, que puede afectar a la validez de las lecturas iniciales de $\mathrm{PtiO}_{2}$. El periodo de estabilización del tejido cerebral es variable, según los diferentes catéteres, aunque la mayoría de autores refieren un tiempo medio de estabilización de 2 horas. Es decir, a partir de las 2 horas de monitorización, los valores de $\mathrm{PtiO}_{2}$ ya pueden considerarse válidos ${ }^{15,36,99}$.

\section{Sensibilidad y desviación del "0"}

En los electrodos de tipo Clark convencionales, la saturación progresiva del cátodo del "revoxode" por iones $\mathrm{OH}$ - disminuye la sensibilidad del electrodo. Sin embargo, en los sensores Licox la modificación del electrodo permite que se establezca una reacción reversible, que evita una disminución significativa de la sensibilidad del sensor durante los primeros 5 días de monitorización. No obstante, se recomienda que al finalizar la monitorización del paciente se analice la desviación de la sensibilidad del sensor y su potencial desviación del " 0 ”. En nuestro centro, durante un periodo inicial de 3 años, una vez retirado el catéter también practicábamos un cultivo del extremo intracraneal para realizar análisis microbiológicos. Eliminados los restos hemáticos con suero fisiológico, el catéter se reintroduce en su funda original para conservar una humedad del 100\%.

Para comprobar la desviación en la sensibilidad del sensor podemos comparar la lectura que el sensor realiza del contenido de $\mathrm{O}_{2}$ de la atmósfera, con la presión real de $\mathrm{O}_{2}$ que contiene en aquel momento el aire atmosférico. Para ello se utiliza una cámara termosellada, en la que la temperatura es constante, y una miniestación metereo-

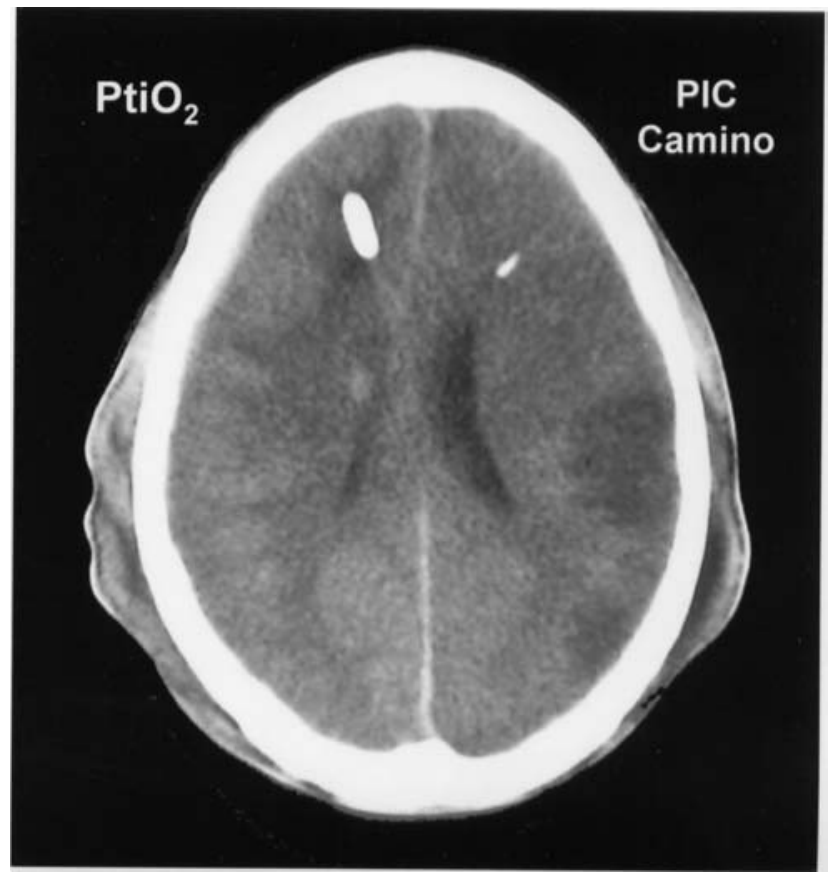

Fig. 5: Artefacto de un sensor de oximetría en una TC cerebral de control. La imagen muestra como la señal del sensor de oximetría (derecha) es incluso más visible que la del sensor de PIC (izquierda).

lógica. El sensor de oximetría explantado se conecta al monitor Licox, el cual nos ofrece una determinada lectura de presión de $\mathrm{O}_{2}$. La lectura del monitor se compara con la lectura esperada, obtenida a partir de tablas convencionales que correlacionan la temperatura ambiente, la altitud y la humedad con la presión de $\mathrm{O}_{2}$ atmosférico. El porcentaje de desviación se calcula a partir de la fórmula: $\left(\mathrm{pO}_{2}\right.$ aire $-\mathrm{pO}_{2}$ esperada $) /\left(\mathrm{pO}_{2}\right.$ esperada $) * 100$, considerándose óptimo que esta desviación sea inferior al 5\%.

Para calcular la desviación del "0", el catéter de oximetría debe depositarse durante unos 20 minutos en una solución libre de $\mathrm{O}_{2}$. Se trata de una solución preparada en farmacia que combina sulfito sódico y bórax en agua bidestilada. La combinación de ambos productos libera el $\mathrm{O}_{2}$ contenido en la solución. En condiciones ideales, la lectura de $\mathrm{PtiO}_{2}$ que se obtenga con esta maniobra debe ser cercana a "0". La figura 6 muestra un proceso de cálculo de la desviación de la sensibilidad y de la desviación del " 0 " después de la retirada de un sensor Licox.

En una serie de 101 pacientes con un TCE publicada por van den Brink y col. ${ }^{99}$, se estableció que el valor medio de la desviación del " 0 " de los sensores fue de sólo $0,42 \pm$ $0,85 \mathrm{mmHg}$ y la desviación de su sensibilidad fue de $0 \pm$ $6 \%$. En otro estudio publicado por Dings y col. ${ }^{15}$, los autores objetivaron que la desviación del " 0 " era incluso más baja $(-0,21 \pm 0,25 \mathrm{mmHg})$, al igual que el error máximo 


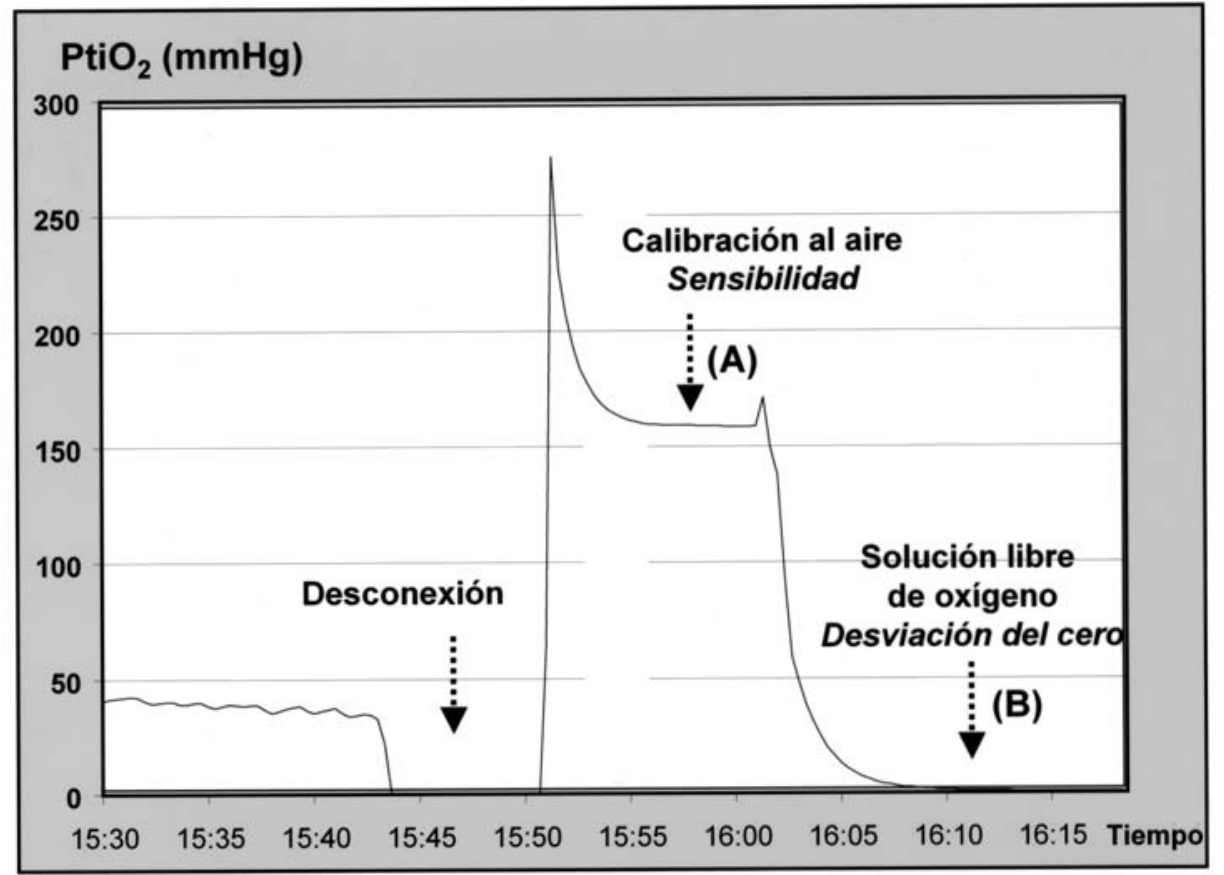

Figura 6. Esquema de los cálculos que se realizan durante la retirada de un sensor de oximetría tisular. A) Cálculo de la desviación de la sensiblidad del sensor: la lectura del sensor se compara con la presión de $\mathrm{O}_{2}$ real de la atmósfera. Esta última se obtiene a partir de la información que proporciona una pequeña estación metereológica. B) Cálculo de la desviación del "0": en este test el sensor se ha introducido en una solución libre de $\mathrm{O}_{2}$.

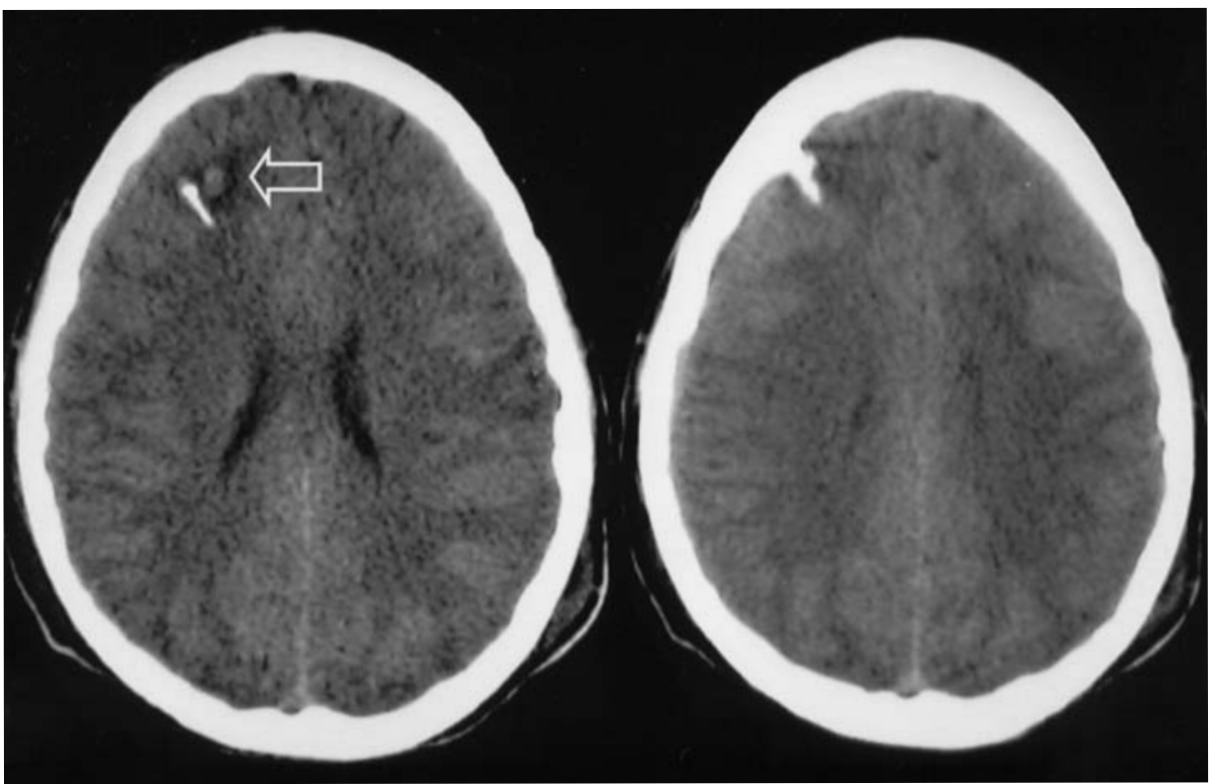

Figura 7. Pequeña hemorragia provocada por la colocación de un sensor de PtiO. El volumen total de la colección hemática era de alrededor de $1 \mathrm{cc}$. La imagen hemática desapareció en las exploraciones radiológicas de control.

detectado en las lecturas de $\mathrm{PtiO}_{2}(1,07 \pm 2,14 \%)$. En una serie de 125 pacientes valorada en nuestro centro el valor medio de la desviación del " 0 " de los sensores Licox ha sido muy semejante a las de los autores anteriores $(0,4 \pm$ $1,5 \mathrm{mmHg}$ ), siendo el error máximo en las lecturas de $\mathrm{PtiO}_{2}$ algo superior $(-4,6 \pm 9,3 \%)$, aunque clínicamente no relevante.

Complicaciones y problemas de malfuncionamiento de los sensores de $\mathrm{PtiO}_{2}$

Entre las potenciales complicaciones asociadas a este sistema de monitorización se encuentran fundamentalmente las infecciones y las hemorragias cerebrales. Sin embargo, ambos tipos de problemas son muy poco frecuentes. En los 84 primeros sensores de oximetría tisular implantados en nuestro centro en 76 pacientes con un TCE grave o moderado, no existió ninguna complicación infecciosa atribuible a la monitorización. Dos de los 76 pacientes $(2,6 \%)$ presentaron una pequeña colección hemática $(<2$ cc de volumen) alrededor de la punta del catéter (Fig. 7). Estos resultados coinciden con los de otras series de la literatura ${ }^{15,16,55,99,100}$.

Los problemas de malfuncionamiento de los sensores 
están claramente relacionados con las manipulaciones del paciente y los traslados a otras dependencias hospitalarias (TC, quirófanos, etc.), y ocurren fundamentalmente durante el periodo de aprendizaje de cada centro. Para evitar la rotura del sensor no debe existir tensión ni acodaduras entre el sensor y el cable del monitor. No obstante, el hecho decisivo que reduce al mínimo la posibilidad de fractura y malfuncionamiento de los sensores es que se extremen las precauciones durante los traslados.

Cuando un sensor no funciona, su lectura permanece fija en el " 0 " o, simplemente, no hay lectura. Una maniobra que permite comprobar el funcionamiento de los sensores es aumentar transitoriamente la $\mathrm{FiO}_{2}$ del respirador. Descartados problemas locales en relación con la punta del sensor (p.e. coágulos), si el sensor funciona las cifras de $\mathrm{O}_{2}$ tisular aumentan.

\section{Controversias relacionadas con la situación óptima del sensor de $\mathrm{PtiO}_{2}$ : ¿hemisferio sano o área de penumbra?}

Al tratarse de una medida eminentemente local, debe considerarse cuál debería ser la situación óptima del sensor, es decir en qué punto éste puede ofrecer la información más útil para el manejo del enfermo. A este respecto, en la literatura existe división de opiniones. Algunos autores consideran que la implantación del sensor en el hemisferio sano ofrece una información que puede extrapolarse al resto del parénquima no lesionado ${ }^{36}$. Para ellos, el objetivo básico sería proteger a este tejido "sano" de la aparición de lesiones secundarias. Sin embargo, otros autores consideran que ya existen otros sistemas de medición globales que ofrecen esta información y apoyan el hecho de que la información más sensible va a proceder de las áreas de penumbra, considerando como tales el tejido que circunda a las lesiones focales $^{36,81}$. Los resultados de algunos estudios también objetivan que la colocación del sensor de $\mathrm{PtiO}_{2}$ en el núcleo o core de una lesión no aporta ninguna información útil para el manejo terapéutico del paciente ${ }^{81}$.

Inicialmente, en nuestro centro colocábamos el sensor de $\mathrm{PtiO}_{2}$ en el hemisferio menos lesionado. El argumento básico era que, al tratarse de una nueva variable, iniciar el estudio de áreas cerebrales alteradas añadía demasiada complejidad en la interpretación de los datos y podía llevar a extraer conclusiones erróneas acerca de esta variable. En el momento actual hemos cambiado nuestra estrategia y los sensores de colocan en función del tipo de lesión. En las lesiones difusas se coloca un sensor en el hemisferio derecho, combinado con el sensor de PIC. En las lesiones focales, siempre que es posible, se colocan dos sensores: uno en el hemisferio cerebral menos lesionado y otro en una área de penumbra.

\section{Controversias relacionadas con la situación óptima del}

\section{sensor de $\mathrm{PtiO}_{2}$ : ¿sustancia gris o sustancia blanca?}

Otro aspecto a considerar es si el sensor debería colocarse en la sustancia gris o en la sustancia blanca. De acuerdo con los esquemas clásicos, la sustancia gris es mucho más sensible que la sustancia blanca a acontecimientos isquémicos de igual magnitud. Dentro de la sustancia gris existen poblaciones de neuronas especialmente susceptibles a la isquemia (células piramidales del hipocampo y neocórtex y neuronas de ciertos ganglios basales). Estos hechos sugerirían que el sensor de $\mathrm{PtiO}_{2}$ debería colocarse en la corteza cerebral. No obstante, un aspecto que suscita cada vez más interés es que la sustancia blanca podría ser más sensible que la gris a los episodios de hipoxia tisular.

Los infartos capsulares aislados y la afectación difusa de la sustancia blanca que con frecuencia se observa en individuos de edad avanzada, y que deriva de situaciones de isquemia crónica (leukoaraiosis), apoyan este argumento. Además, estudios experimentales en modelos de isquemia focal han objetivado que los cambios celulares, indicativos de lesión estructural, aparecen de forma más precoz y agresiva en la sustancia blanca subcortical que en el córtex del territorio cerebral del vaso ocluido. La tumefacción de los oligodendrocitos, astrocitos y axones, así como los cambios vacuolares en la mielina que envuelve al axolema, aparecen de forma precoz (primeros 30 minutos de la oclusión arterial) y preceden a los cambios de las neuronas corticales del territorio afecto. La explicación más plausible para estos hallazgos se encontraría en la especial distribución del árbol vascular del encéfalo.

En el córtex cerebral existe una gran densidad de capilares. Este hecho permite que, frente a un acontecimiento isquémico, los capilares adyacentes inicialmente puedan compensar la falta de irrigación de las neuronas corticales afectas. En cambio, la irrigación de la sustancia blanca es terminal y su densidad de capilares es muy inferior a la de la sustancia gris, lo que condiciona una menor protección frente a la isquemia tisular. Estos argumentos sugieren que la situación ideal del catéter de $\mathrm{PtiO}_{2}$ debería ser la sustancia blanca subcortical. Los sensores situados en la sustancia blanca ofrecen valores de $\mathrm{PtiO}_{2}$ más estables ${ }^{56}$, aunque inferiores a los que se obtienen a medida que el sensor se retira hasta situarse en el córtex cerebral ${ }^{15}$.

Colocado el catéter en una situación subcortical, el último aspecto a considerar es el territorio óptimo a monitorizar. Dado que las regiones frontera entre dos territorios vasculares son las más vulnerables a la isquemia cerebral, el catéter debería situarse en una de estas áreas. En nuestro centro, y en las lesiones difusas, habitualmente el catéter se implanta en la región frontal derecha, en el territorio frontera entre las arterias cerebral media y cerebral anterior (Fig. 8). Para situar el catéter de $\mathrm{PtiO}_{2}$ en esta 


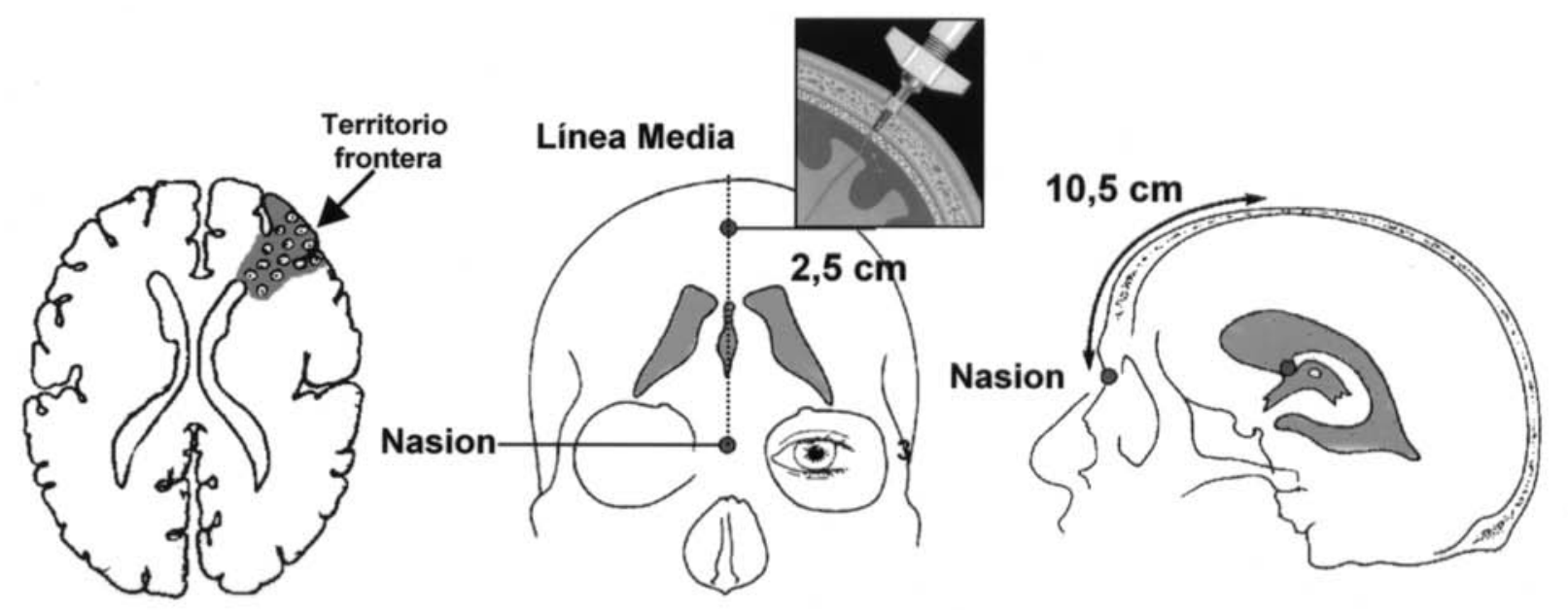

Figura 8. Esquema del área seleccionada para la implantación de un sensor de PtiO. Se trata de un territorio frontera entre la arteria cerebral media y la arteria cerebral anterior. Las referencias anatómicas que utilizamos para practicar la craneostomía a este nivel son: $10,5 \mathrm{~cm}$ del nasion y unos $2,5 \mathrm{~cm}$ de la línea media.

posición, la craneostomía debe practicarse a unos $10,5 \mathrm{~cm}$ del nasion y a unos $2,5 \mathrm{~cm}$ de la línea media, siguiendo el mismo trayecto que se utiliza para la colocación de un drenaje ventricular.

Métodos regionales y globales de monitorización cere-

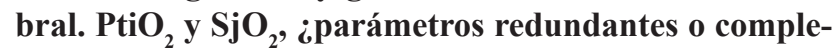
mentarios?

La inclusión de la $\mathrm{PtiO}_{2}$ en la monitorización del paciente neurocrítico ha obligado a los clínicos a profundizar en el significado fisiopatológico de esta nueva variable; esto explica por qué diversos autores han comparado la información que ofrece la $\mathrm{PtiO}_{2}$ con la que ofrecen otros sistemas de monitorización de la oxigenación cerebral ${ }^{31,34,35,51}$. Kiening y col. ${ }^{51}$ observaron que la $\mathrm{SjO}_{2}$ y la $\mathrm{PtiO}_{2}$ presentaban cambios paralelos en situaciones de hipotensión arterial. Descensos de un $10 \%$ en la $\mathrm{SjO}_{2}$ se correlacionaban con un descenso medio de la $\mathrm{PtiO}_{2}$ de 6 $\mathrm{mmHg}^{51}$. Al analizar los cambios paralelos entre ambas variables, estos autores establecieron que el umbral de isquemia de la $\mathrm{SjO}_{2}(50 \%)$ se correspondía a valores de entre 3 y $12 \mathrm{mmHg}\left(\right.$ media de 8,5) de $\mathrm{PtiO}_{2}^{51}$. Cuando la $\mathrm{SjO}_{2}$ caía a niveles del $30 \%$, la $\mathrm{PtiO}_{2}$ se acercaba a $0 \mathrm{mmHg}$ y valores de $\mathrm{SjO}_{2}$ del $70 \%$ se correspondían con valores de unos $20 \mathrm{mmHg}$ de $\mathrm{PtiO}_{2}{ }^{51}$. Otro hallazgo importante de este estudio fue que las lecturas de $\mathrm{PtiO}_{2}$ se mostraron estables en un $95 \%$ del tiempo de registro, porcentaje muy superior al que habitualmente ofrece la monitorización de la $\mathrm{SjO}_{2}{ }^{51}$.

Gopinath, Fandino y otros autores también han realizado estudios comparativos entre la $\mathrm{SjO}_{2}$ y la $\mathrm{PtiO}_{2}^{22,31,34}$. Estos estudios han coincidido en que existe una buena correlación entre ambas variables. Sin embargo, todos ellos demuestran que existe un porcentaje elevado de casos en los que la isquemia sólo se detecta a partir de una de las dos

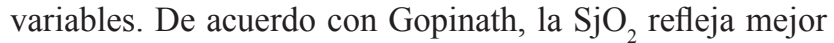
los cambios que se producen durante la hiperventilación, mientras que la $\mathrm{PtiO}_{2}$ traduce mejor los cambios en la $\mathrm{pO}_{2}$ arterial $^{31}$. En situaciones de isquemia cerebral global y grave, la $\mathrm{PtiO}_{2}$ cae y permanece en $0 \mathrm{mmHg}$, mientras que la $\mathrm{SjO}_{2}$ inicialmente puede descender y, cuando el FSC cesa, asciende hasta valores $>90 \%$, indicando la ausencia de consumo metabólico de $\mathrm{O}_{2}$ (necrosis tisular).

Estudios de tomografía computarizada por emisión de positrones (SPECT) y Xenón-TC confirman que el FSC en las lesiones focales es heterogéneo, lo que puede explicar las discrepancias de los valores de $\mathrm{PtiO}_{2}$ y $\mathrm{SjO}_{2}$, sin que ello reste valor a ninguna de las dos variables. Por otra parte, en monitorizaciones bilaterales del bulbo de la yugular se ha objetivado que los valores de la $\mathrm{SjO}_{2}$ pueden diferir, en función de la dominancia del drenaje venoso cerebral ${ }^{89}$. También se ha confirmado que la colocación de dos catéteres de $\mathrm{PtiO}_{2}$ en regiones tisulares con diferente grado de lesión puede mostrar valores diferentes, aunque presentan las mismas tendencias en sus cambios ${ }^{50}$. Estos hallazgos indican la complejidad del estudio de la oxigenación cerebral y apoyan que en el momento actual no debería prescindirse de una medición global como la $\mathrm{SjO}_{2}$, ya que esta variable complementa la información que ofrece una variable local como la $\mathrm{PtiO}_{2}$. La figura 9 muestra un ejemplo de lecturas aparentemente paradójicas entre la $\mathrm{SjO}_{2}$ y la $\mathrm{PtiO}_{2}\left(\mathrm{SjO}_{2}>90 \%\right.$, en el contexto de un hemisferio hipodenso en la TC cerebral y lecturas supranormales de la $\mathrm{PtiO}_{2}$ ) que confirma la ventaja de utilizar sistemas de monitorización globales combinados con sistemas regionales. 
Figura 9. Imágenes de una TC $y$ de una SPECT cerebral practicadas de forma secuencial en un paciente con un TCE grave. Este paciente presentaba una $\mathrm{PtiO}_{2}$ extremadamente elevada en el contexto de un hemisferio cerebral hipodenso y lecturas de $\mathrm{SjO}_{2}$ de 63\%. Sin embargo, al practicar la SPECT cerebral se observó que en el área en la que se hallaba situado el sensor de oximetría tisular existía una zona de máxima hiperemia alrededor de zonas hipoperfundidas. Estos hallazgos confirman la heterogeneidad del FSC, la fiabilidad de la $\mathrm{PtiO}$ y la ventaja de monitorizar de forma simultánea parámetros que ofrecen una información global ( $\left.\mathrm{SjO}_{2}\right)$ con otros que aportan una información regional ( $\mathrm{PtiO}_{2}$ ) sobre la oxigenación cerebral.

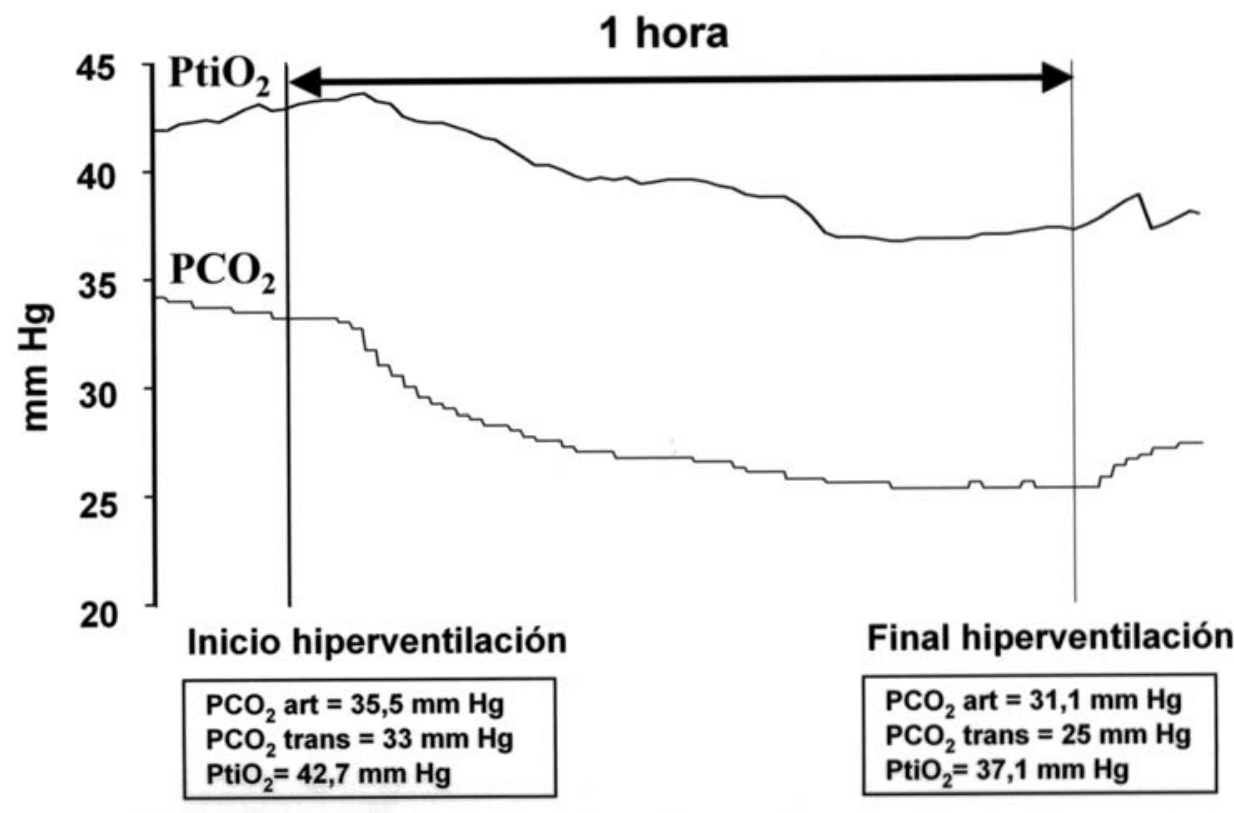

Figura 10. Test de hiperventilación en dos pacientes con un TCE. En la imagen se observa que el descenso de $\mathrm{PaCO}_{2}$ provoca una caída de la $\mathrm{PtiO}_{2}$. Los cambios en la presión de $\mathrm{CO}_{2}$ se monitorizaron a partir de un monitor de gases transcutáneos (Radiometer) y fueron validados por mediciones gasométricas puntuales.

Influencia de la $\mathrm{PaCO}_{2}, \mathrm{PaO}_{2}, \mathrm{PIC}$ y $\mathrm{PPC}$ en la $\mathrm{PtiO}_{2}$

Diversos autores han estudiado la influencia de la hiperventilación sobre la $\mathrm{PtiO}_{2}$, con resultados aparentemente paradójicos. Descensos de la $\mathrm{PaCO}_{2}$ condicionan una vasoconstricción arteriolar, que debería traducirse en un descenso de la $\mathrm{PtiO}_{2}$ (Fig. 10). Sin embargo, los diferen- tes estudios practicados a este respecto indican que si bien este tipo de respuesta aparece en algunos casos ${ }^{14,22,34,37,58,65}$, existe un número importante de pacientes en los que la oxigenación tisular no se modifica o incluso aumenta ${ }_{13,100}$. En nuestro centro también hemos observado diferentes tipos de respuestas. La respuesta de la $\mathrm{PtiO}_{2}$ a la hiperventilación no se correlaciona de forma clara con el pronóstico de los 


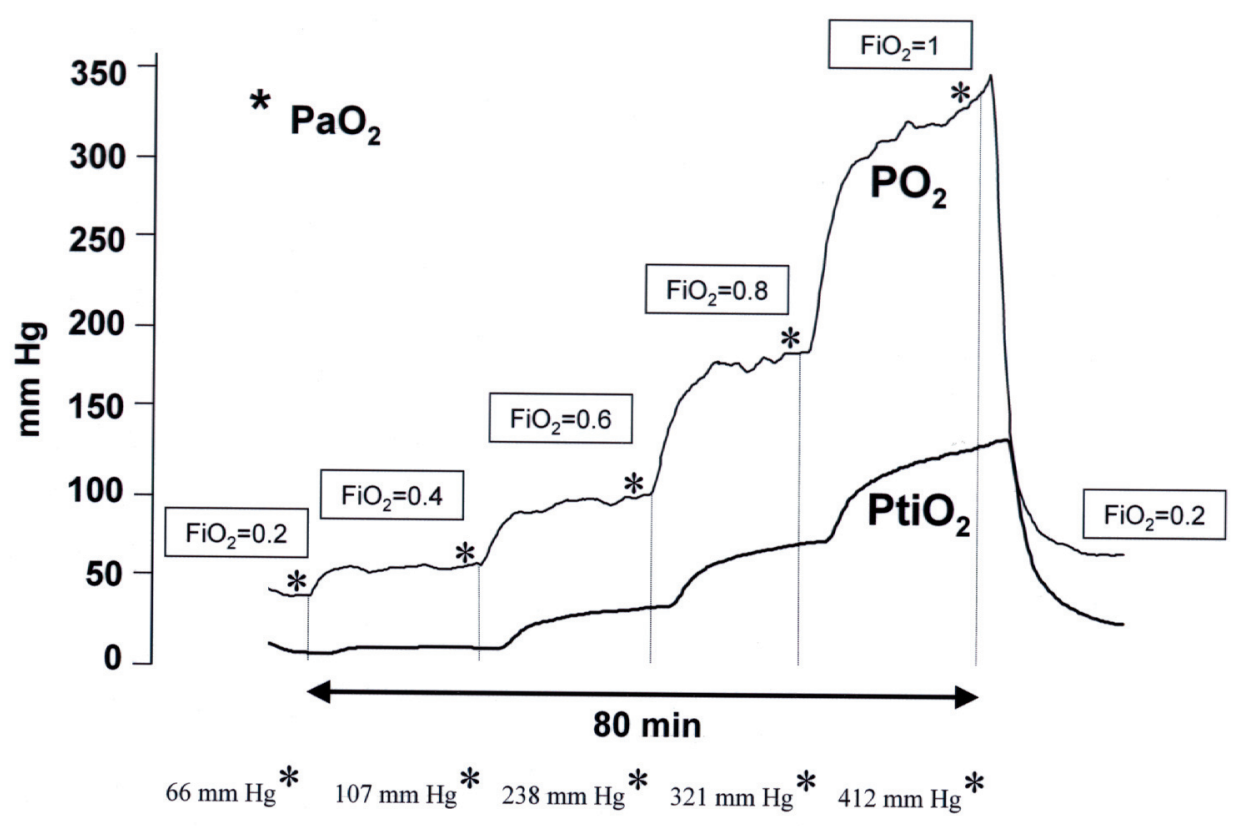

Figura 11. Test de hiperoxia. $\mathrm{La} \mathrm{PtiO}$, del paciente asciende de forma paralela al aumento de la $\mathrm{FiO}_{2}$. Los cambios en la presión de $\mathrm{O}$, también pueden observarse a nivel periférico a partir de la monitorización simultánea de gases transcutáneos (Radiometer). Los asteriscos muestran las mediciones puntuales de la $\mathrm{PaO}_{2}$ obtenidas a partir de análisis gasométricos convencionales.

pacientes, lo que coincide con el hecho de que la vasoreactividad cerebral al $\mathrm{CO}_{2}$ puede ser heterogénea.

La reactividad cerebral al $\mathbf{O}_{2}$ se estudia a partir de tests de hiperoxia, en los que la $\mathrm{FiO}_{2}$ se incrementa de forma controlada y transitoria. De acuerdo con conceptos clásicos, está establecido que cuando la concentración de hemoglobina es normal, su saturación es completa y existe una correcta disociación entre la $\mathrm{Hb}$ y el $\mathrm{O}_{2}$, el incremento de la $\mathrm{PaO}_{2}$ arterial no aporta beneficios significativos en la oxigenación tisular. Sin embargo, al estudiar la reactividad cerebral al $\mathrm{O}_{2}$ se ha demostrado que cuando se incrementa la $\mathrm{FiO}_{2}$ se observa de forma casi constante un aumento paralelo de la $\mathrm{PtiO}_{2} 22,36,59,65,67$ (Fig. 11). Queda por dilucidar el significado de esta respuesta.

Menzel y col..$^{67,68}$ objetivaron que el aumento de $\mathrm{FiO}_{2}$ podía disminuir la producción cerebral de lactato. Sin embargo, otros autores destacaron que la hiperoxia provocaba no sólo un descenso en los niveles de lactato sino también del piruvato, lo que podía conducir a diferentes interpretaciones fisiopatológicas ${ }^{57}$. En el momento actual, el papel terapéutico de la hiperoxia continúa siendo un motivo de debate ${ }^{10}$. Por otra parte, Meixenberg y col. observaron que el aumento de $\mathrm{PtiO}_{2}$ era más evidente en el tejido edematoso que en el tejido cerebral normal ${ }^{65}$. Lo cual sugiere que en el tejido edematoso se alteran los mecanismos de regulación que controlan la $\mathrm{PtiO}_{2}$ y que este podría ser un dato de mal pronóstico. No obstante, la relación pronóstica entre los cambios de $\mathrm{PtiO}_{2}$ frente a las modificaciones de $\mathrm{PaO}_{2}$ no ha sido confirmada por otros autores y debe contemplarse con cautela. Como hemos comentado, en la práctica clínica el incremento de $\mathrm{PtiO}_{2}$ frente a cambios en la $\mathrm{FiO}_{2}$ se utiliza como una maniobra de comprobación del correcto funcionamiento del catéter de oximetría cerebral.

La hipertensión intracraneal puede comprometer la oxigenación tisular, tal y como hemos observado en nuestros pacientes en repetidas ocasiones. Del mismo modo, un descenso en la PPC por debajo del umbral de la autorregulación puede inducir hipoxia tisular ${ }^{37}$. Al analizar la influencia de la PPC en la oxigenación tisular se ha objetivado que caídas de la PPC suelen asociarse a descensos de la $\mathrm{PtiO}_{2}{ }^{9,37,88}$. Stocchetti y col.$^{88}$ constataron que al incrementar la PPC se conseguían aumentos de la $\mathrm{PtiO}_{2}$ en áreas cerebrales lesionadas, especialmente cuando la $\mathrm{PtiO}_{2}$ presentaba valores basales bajos. De acuerdo con estos hallazgos, la influencia de los cambios en la PPC sobre la oxigenación tisular podría determinar la efectividad de la manipulación de la PPC y ayudar a establecer los umbrales óptimos de PPC en estos pacientes.

Kiening y col. ${ }^{49}$ objetivaron que los descensos de PPC por debajo de $60 \mathrm{mmHg}$ provocaban importantes reducciones en la $\mathrm{PtiO}_{2}$. Sin embargo, el incremento de la PPC por encima de este umbral no mejoraba la oxigenación cerebral ${ }^{49}$. En un estudio reciente, Sahuquillo y col.$^{80}$ han objetivado que valores supranormales de PPC pueden coexistir con una hipoxia tisular y que los incrementos de PPC no siempre se acompañan de aumentos paralelos en la $\mathrm{PtiO}_{2}$.

\section{Valor pronóstico de la $\mathrm{PtiO}_{2}$}

En la fase aguda del traumatismo, se ha constatado que los valores de $\mathrm{PtiO}_{2}$ suelen ser bajos, incluso después del periodo de estabilización del catéter. Van den Brink y col. ${ }^{99}$ demostraron que más del $50 \%$ de los pacientes con un TCE 
grave presentaban valores bajos de $\mathrm{PtiO}_{2}$ durante las primeras 12-24 horas después del traumatismo. Cuarenta de sus 101 pacientes presentaron valores de $\mathrm{PtiO}_{2}$ por debajo de $10 \mathrm{mmHg}$ y en 22 casos estas cifras fueron inferiores a los $5 \mathrm{mmHg}^{99}$. Estos hallazgos coinciden con los valores bajos de las velocidades del Doppler transcraneal y la reducción del FSC que diversos autores han observado en la fase aguda del traumatismo, pudiendo corresponder a lo que Martin y col. denominaron "fase I o fase de hipoperfusión cerebral" ${ }^{\prime 61}$. Sin embargo, diversos autores afirman que las lecturas bajas de $\mathrm{PtiO}_{2}$ se asocian a un mal pronóstico $^{3,17,97,99}$.

El límite inferior del rango de normalidad que se ha establecido para la $\mathrm{PtiO}_{2}$ se sitúa en $15 \mathrm{mmHg}$. Valores inferiores indicarían una hipoxia tisular cerebral. De acuerdo con Valadka y col. ${ }^{97}$, la probabilidad de muerte de los pacientes se incrementa cuando la $\mathrm{PtiO}_{2}$ es inferior a $15 \mathrm{mmHg}$ y el mal pronóstico es casi constante cuando las lecturas son inferiores a $6 \mathrm{mmHg}$, independientemente de la duración de los periodos de hipoxia. Van den Brink y col. ${ }^{99}$ también demostraron que la duración y la severidad de la hipoxia tisular $\left(\mathrm{PtiO}_{2}<10 \mathrm{mmHg}\right)$ se correlacionaba de manera significativa con un mal resultado neurológico.

A pesar de los hallazgos de estos autores, el significado pronóstico de las lecturas bajas de $\mathrm{PtiO}_{2}$ debe considerarse con cautela, ya que pueden existir artefactos metodológicos (microhemorragias en la punta del sensor...) que dificulten la difusión de $\mathrm{O}_{2}$ hasta el catéter. Por otra parte, el resultado final de los pacientes neurotraumáticos es multifactorial y no puede, ni debe, establecerse a partir de un único parámetro. En el momento actual se considera, no obstante, que dada la asociación entre valores bajos de $\mathrm{PtiO}_{2}$ y mal pronóstico los objetivos terapéuticos en los pacientes con un TCE grave deben dirigirse a mantener cifras correctas no sólo de PIC y PPC, sino también de $\mathrm{PtiO}_{2}$.

\section{Diagnóstico diferencial de la hipoxia tisular a partir de la $\mathrm{PtiO}_{2}$ y otras variables}

En condiciones normales existe un equilibrio entre el aporte cerebral de $\mathrm{O}_{2}$ y sus demandas metabólicas. La $\mathrm{PtiO}_{2}$ refleja el balance entre aporte y consumo de $\mathrm{O}_{2}$ a nivel tisular ${ }^{36,48}$. El aporte de $\mathrm{O}_{2}$ al encéfalo depende del FSC, el cual se regula a nivel de la microcirculación, a partir de complejas interacciones entre células endoteliales y neuronas y fenómenos metabólicos que actúan a nivel de las arterias, arteriolas y esfínteres precapilares. Para que el aporte tisular de $\mathrm{O}_{2}$ sea efectivo, debe existir también una correcta difusión de las moléculas de $\mathrm{O}_{2}$ desde la hemoglobina al espacio extracelular y, posteriormente, al interior de la célula. La difusión se establece a favor de un gradiente de $\mathrm{PO}_{2}$ y depende de la concentración de la hemoglobina y de su afinidad por el $\mathrm{O}_{2} \mathrm{y}$, en último término, de la cantidad de $\mathrm{O}_{2}$ disuelto en sangre.

Las alteraciones en el espacio extracelular, que pueden aparecer en el contexto de un edema cerebral o en presencia de lesiones estructurales, (disminución de la densidad de capilares funcionales y aumento de la distancia intercapilar), también dificultan el acceso del $\mathrm{O}_{2}$ a las células y reducen la presión parcial del $\mathrm{O}_{2}$ intracelular. Por último, hay que añadir que valores normales de la $\mathrm{PtiO}_{2}$ no garantizan que la célula realice un correcto uso del $\mathrm{O}_{2}$, ya que pueden existir casos en los que alteraciones estructurales o funcionales de las mitocondrias impidan una correcta utilización del $\mathrm{O}_{2}$. Existen, por tanto, diferentes causas de hipoxia tisular en el cerebro, por lo que es importante establecer un diagnóstico diferencial entre ellas. La monitorización continua de la $\mathrm{PtiO}_{2}$, combinada con la información que ofrecen otras variables hemometabólicas, pueden ayudar a establecer la etiología de la hipoxia tisular.

Sahuquillo y col. $^{79}$ objetivaron que algunos pacientes presentaban situaciones de hipoxia tisular $\left(\mathrm{PtiO}_{2}<\right.$ $15 \mathrm{mmHg}$ ) en el contexto de un FSC normal o de un cerebro hiperémico, de acuerdo con medidas globales como la fracción de extracción cerebral de $\mathrm{O}_{2}\left[\mathrm{CEO}_{2}=\right.$ $\left.\left(\mathrm{CaO}_{2}-\mathrm{CjO}_{2} / \mathrm{CaO}_{2}\right) * 100\right]$. En un estudio con 61 pacientes neurotraumáticos, estos autores confirmaron que la mayoría de los episodios de hipoxia tisular se debían a situaciones de alta afinidad entre la hemoglobina y el $\mathrm{O}_{2}$ (por ejemplo durante la hipotermia moderada o hipotermia asociada con hipocapnia), a casos de hipoxia por disperfusión o a hipoxias por "shunt", de acuerdo a la clasificación de Siggaard-Andersen ${ }^{86}$. La hipoxia por disperfusión y la hipoxia secundaria a "shunts" no pueden diferenciarse desde el punto de vista clínico. Sahuquillo y col. ${ }^{79}$ proponen en este artículo aplicar una modificación de la clasificación de Siggaard-Andersen al estudio del encéfalo, con el objetivo de identificar la causa más probable de hipoxia tisular en los pacientes con un TCE grave. La Tabla 1 resume las posibles causas de hipoxia tisular y las variables adicionales que se requieren para su diagnóstico.

\section{MICRODIÁLISIS CEREBRAL}

Las técnicas de microdiálisis ofrecen información directa sobre diversos aspectos metabólicos del tejido estudiado: disponibilidad de sustratos como la glucosa y producción de diversos metabolitos y neurotransmisores. La aplicación de estas técnicas al estudio del encéfalo se inició en la década de los sesenta, utilizándolas en animales de experimentación ${ }^{6,26}$. Delgado y Defeudis en 1972 y posteriormente Ungerstedt adaptaron la microdiálisis al estudio del encéfalo humano ${ }^{12,42,93,95}$. En el momento actual, la microdiálisis cerebral se está introduciendo de forma progresiva en la monitorización de los pacientes neurocríticos, ya que ofrece una importante información neurometabólica 
TABLA

Tipos de hipoxia tisular cerebral*

\begin{tabular}{|c|c|c|c|c|c|}
\hline Tipo de hipoxia & Causa & $\begin{array}{l}\mathrm{SjO}_{2} \\
(\%)\end{array}$ & $\begin{array}{c}\mathrm{PtiO}_{2} \\
(\mathrm{~mm} \mathrm{Hg})\end{array}$ & $\underset{(\mathbf{m m ~ H g} \mathbf{H})}{\mathbf{P}_{50}}$ & $\begin{array}{c}\text { Px } \\
(\mathbf{m m ~ H g})\end{array}$ \\
\hline Hipoxia isquemica & $\boldsymbol{V}_{\text {Flujo sanguineo cerebral }}$ & $\downarrow$ & $\leq 15$ & $24-29$ & $\mathrm{~N}$ \\
\hline $\begin{array}{l}\text { Hipoxia por baja } \\
\text { extractibilidad }\end{array}$ & $\begin{array}{l}\text { - Hipoxemia } \\
\text { - Anemia } \\
\text { - Alta afinidad entre } \mathrm{Hb}_{\text {y } \mathrm{O}_{2}}\end{array}$ & 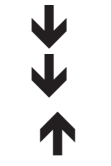 & $\begin{array}{l}\leq 15 \\
\leq 15 \\
\leq 15\end{array}$ & $\begin{array}{l}24-29 \\
24-29 \\
\leq 24\end{array}$ & $\downarrow$ \\
\hline Hipoxia por shunt & Shunts arterio-venosos & N/T & $\leq 15$ & $24-29$ & $\mathrm{~N}$ \\
\hline Hipoxia por disperfusión & $\begin{array}{l}\text { Dificultades en la difusion } \\
\text { del } \mathrm{O}_{2} \text { desde la } \mathrm{Hb} \text { a la } \\
\text { mitocondria }\end{array}$ & N/T & $\leq 15$ & $24-29$ & $\mathrm{~N}$ \\
\hline Hipoxia histotóxica & $\begin{array}{l}\text { Inhibicion de los citocromos } \\
\text { mitocondriales }\end{array}$ & $\mathrm{N} / \boldsymbol{\top}$ & $\mathrm{N}$ & $24-29$ & $\mathrm{~N}$ \\
\hline Hipoxia por desacoplamiento & $\begin{array}{l}\text { Desacoplamiento entre la } \\
\text { reduccion del O } \\
\text { y la sintesis de ATP }\end{array}$ & $\mathrm{N} / \boldsymbol{T}$ & $\mathrm{N}$ & $24-29$ & $\mathrm{~N}$ \\
\hline Hipoxia hipermetabólica & $\begin{array}{l}\text { Incremento de las } \\
\text { necesidades metabolicas }\end{array}$ & $\downarrow$ & $\leq 15$ & $24-29$ & $\mathrm{~N}$ \\
\hline
\end{tabular}

*Tabla que define los diferentes tipos de hipoxia tisular cerebral a partir be la clasificacion de Siggaard-Andersen adaptada al encefalo ${ }^{86}$ Tabla modificada de Sahuquillo y col. ${ }^{79}$. Hb: hemoglobina. N: rango de normalidad. $\mathrm{P}_{50}$ : Presión de $\mathrm{O}_{2}$ en el que la Hb se encuentra saturada en un 50\%. Px: Presión de extracción de $\mathrm{O}_{2}$.

complementaria a las variables que de forma rutinaria se monitorizan en estos pacientes (PIC, $\left.\mathrm{PPC}, \mathrm{SjO}_{2} \ldots\right)^{33,44,48}$.

\section{Fundamentos y objetivos}

Desde un punto de vista conceptual, la microdiálisis es una técnica basada en el principio del intercambio de solutos a través de una membrana semipermeable, que emula el funcionamiento de un capilar y cuyos objetivos básicos son: 1) monitorizar la disponibilidad tisular de diferentes metabolitos, 2) monitorizar los elementos liberados por las células y 3) monitorizar las consecuencias celulares de la hipoxia-isquemia tisular. La membrana semipermeable se encuentra en el extremo distal del catéter de microdiálisis y a su través se intercambian solutos entre una solución de composición conocida y el líquido contenido en el espacio extracelular. El análisis del microdializado obtenido per- mite cuantificar diversos metabolitos derivados de rutas metabólicas fisiológicas o productos que se producen como resultado de una lesión tisular.

Uno de los objetivos fundamentales del tratamiento de los pacientes con un TCE grave es la prevención de lesiones cerebrales secundarias, de aquí la importancia de poder realizar una detección precoz de la isquemia tisular cerebral. En el encéfalo, la colocación de un catéter de microdiálisis permite el análisis y cuantificación de los cambios que se producen en diversos metabolitos "energéticos" como: lactato, piruvato, adenosina, inosina o hipoxantina. También permite estudiar la liberación de neurotransmisores y neuromoduladores (glutamato, aspartato, taurina, GABA...) o la liberación de productos de degradación tisular (glicerol). Sin embargo, para que esta información sea válida deben considerarse algunos aspectos metodológicos. Además, la información obtenida por 


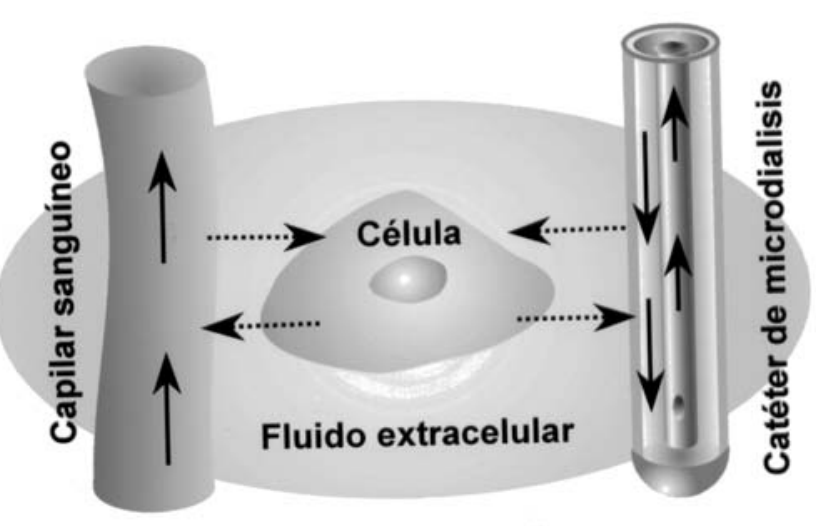

Figura 12. Esquema del funcionamiento del extremo distal (intracerebral) de un catéter de microdiálisis (modificación de una imagen cedida por el Dr. U. Ungerstedt). En el extremo distal se encuentra la membrana semipermeable a través de la cual difunden los iones y moléculas contenidas en el líquido del espacio intersticial. El funcionamiento de estos catéteres se asemeja a la función de un capilar tisular.

los catéteres cerebrales debe contrastarse con la información proporcionada por un catéter adicional colocado en el tejido subcutáneo. Este último aporta información sobre el metabolismo sistémico (extracerebral).

Por último, es importante remarcar que la instauración de este sistema de monitorización requiere un aprendizaje y una disposición de recursos técnicos y humanos que en el momento actual limitan su uso a determinadas unidades de pacientes neurocríticos. Los interesados en adquirir información adicional sobre los últimos avances de este nuevo sistema de monitorización pueden consultar, entre otras fuentes, la página web: www.microdialysis.com, siendo especialmente relevante el apartado de bibliografía, en el que puede accederse a un gran número de artículos relacionados con las técnicas de microdiálisis ${ }^{94}$.

\section{Aspectos metodológicos de la microdiálisis cerebral}

Los catéteres de microdiálisis (CMA-70, CMA Microdialysis, Estocolmo, Suecia) son elementos flexibles, de pequeño diámetro, que contienen una doble luz y en cuyo extremo se sitúa una membrana semipermeable. A través de esta membrana se produce el paso de pequeñas moléculas, que difunden libremente a favor de un gradiente osmótico (Fig. 12). La luz interna del catéter contiene una solución libre de las moléculas a estudiar (solución Ringer sin lactato o suero salino isotónico). Cada uno de los catéteres necesarios (cerebral y sistémico) se acopla a una bomba de infusión continua (CMA-106, CMA Microdialysis), que

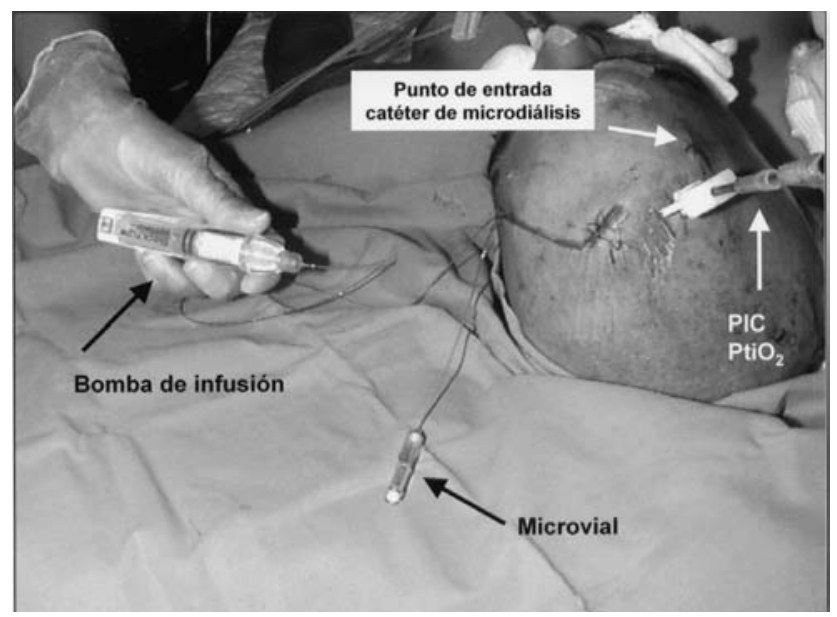

Figura 13. Elementos básicos de la microdiálisis cerebral. En la imagen puede apreciarse el catéter de microdiálisis de doble luz, la bomba de infusión con jeringa que contiene con 2,5 $\mathrm{mL}$ de solución dializante, suficiente para una monitorización continua durante 5 días y el microvial recolector conectado a la segunda luz del catéter de microdiálisis.

infunde la solución a una velocidad constante y predeterminada. En el extremo distal del catéter, y a través de la membrana semipermeable, se produce un intercambio de solutos de un determinado peso molecular.

El microdializado obtenido contiene moléculas procedentes del espacio extracelular y fluye a través de la luz externa del catéter, recuperándose a través de microviales que se sustituyen periódicamente (Fig. 13). Un equipo analizador portátil (CMA-600, CMA Microdialysis) analiza el microdializado mediante técnicas enzimáticas y fluorimétricas (urea) y cuantifica los cambios que se han producido en la composición inicial de la solución.

Los metabolitos disueltos en el fluido del espacio extracelular encefálico proceden de los capilares tisulares, de las neuronas y de las células gliales adyacentes ${ }^{93}$. El paso de sustancias al catéter de microdiálisis depende de su peso molecular (la membrana semipermeable del catéter habitual sólo permite el paso de iones y moléculas de peso molecular inferior a $20.000 \mathrm{Da}$ ), de la velocidad de infusión del fluido de perfusión, de la longitud de la membrana y del coeficiente de difusión de cada sustancia en el tejido a estudiar ${ }^{40}$.

La recuperación de un determinado metabolito se define como la concentración de dicho elemento que contiene el microvial dividida por la concentración real en el espacio intersticial, fracción que se expresa en tanto por cien $^{93}$. La recuperación óptima de todo metabolito debería ser del $100 \%$, es decir: la información proporcionada por el catéter de microdiálisis debería reflejar con exactitud 
la composición del espacio extracelular. En un estudio reciente, Hutchinson y col. ${ }^{41}$ analizaron la influencia de diversos aspectos metodológicos en la recuperación de analitos como la glucosa, el lactato, el piruvato y el glutamato cerebrales en pacientes neuroquirúrgicos. Estos autores confirmaron que las concentraciones de estos metabolitos obtenidas a partir de catéteres adyacentes eran prácticamente idénticas ${ }^{41}$.

En el mismo estudio, cuando se analizó la influencia de la longitud de la membrana de diálisis, se observó que la recuperación de metabolitos era muy superior si se utilizaban membranas dializantes de $30 \mathrm{~mm}$ en lugar de las de 10 $\mathrm{mm}^{41}$. Los autores también comprobaron que la velocidad de perfusión del líquido dializante influía de manera significativa, siendo la velocidad de $0,3 \mu \mathrm{L} / \mathrm{min}$ la que ofrecía mayores ventajas ${ }^{41}$. Utilizando una membrana de diálisis de $10 \mathrm{~mm}$ y una velocidad de infusión de $0,3 \mu \mathrm{L} / \mathrm{min}$, estos autores obtenían una recuperación aproximada del 70\% de todos los metabolitos estudiados ${ }^{40,41}$. Coincidiendo con estos resultados, Ungerstedt y col. objetivaron que con una velocidad de flujo de $0,3 \mu \mathrm{L} / \mathrm{min}$ y una longitud de membrana de $30 \mathrm{~mm}$ la recuperación era de casi el 100\% ${ }^{93,96}$.

Otro aspecto importante que también objetivó el estudio de Hutchinson y col. ${ }^{41}$ es que las muestras analizadas a cabecera del paciente (análisis on-line con el equipo analizador CMA-600) mostraron una excelente correlación, con mínimas diferencias en los valores absolutos, con determinaciones off-line utilizando técnicas cromatográficas (HPLC). Asimismo, la congelación de las muestras de microdiálisis a una temperatura de $-70^{\circ} \mathrm{C}$ durante un periodo de tres meses tampoco alteró de manera significativa las determinaciones obtenidas, constatando que las diferencias en todos los elementos estudiados eran inferiores al $5 \%{ }^{41}$. Por último, estos autores también confirmaron que la utilización de soluciones de Ringer sin lactato o suero salino isotónico no influía en la concentración final de glucosa, lactato, piruvato o glutamato. No obstante, Ungerstedt y col. ${ }^{94}$ recomiendan la utilización de Ringer sin lactato como fluido a perfundir, fundamentándose en que la utilización de suero salino provoca una deplección de calcio y potasio que puede alterar la neurotransmisión en las zonas próximas al catéter implantado.

\section{Metabolitos a determinar: iones, neurotransmisores, marcadores de isquemia y lesión tisular}

A pesar de que los catéteres de microdiálisis cerebral permiten la obtención de un gran número de moléculas e iones, en la práctica clínica la monitorización neuroquímica se limita a la cuantificación secuencial de cuatro metabolitos, número máximo que permite el equipo analizador situado en la cabecera del paciente. En nuestro centro seleccionamos inicialmente glucosa, lactato, piruvato y gli- cerol, en un intento de monitorizar marcadores de isquemia cerebral y lesión tisular. Posteriormente, el glicerol se sustituyó por urea, metabolito que permite realizar un control de calidad adicional sobre la información obtenida (ver apartado correspondiente). El equipo analizador estándar (CMA-600) permite la cuantificación de cuatro analitos por paciente y la monitorización de tres pacientes simultáneos. Sin embargo, si se preservan los microviales a la temperatura adecuada $\left(-70^{\circ} \mathrm{C}\right)$, pueden realizarse determinaciones posteriores de analitos adicionales ${ }^{41}$, siendo la única limitación el volumen residual de fluido dializado que contiene el microvial.

La glucosa es el metabolito determinado con mayor frecuencia en las técnicas de microdiálisis. La glucosa constituye el sustrato energético fundamental del encéfalo. $\mathrm{Su}$ concentración extracelular depende de la concentración de glucosa en sangre periférica, del flujo capilar local y de la captación celular. Esta última puede variar cuando el metabolismo celular deriva de una vía aerobia a una vía anaerobia. La utilización simultánea de un catéter de microdiálisis situado en el tejido subcutáneo proporciona una información continua sobre la disponibilidad sistémica de glucosa, información básica para la correcta interpretación de los niveles de glucosa cerebral. De este modo, cuando desciende la glucosa del encéfalo de forma paralela al $\mathrm{O}_{2}$ tisular $\left(\mathrm{PtiO}_{2}\right)$, conservándose la glucosa periférica, podemos afirmar que existe una disminución de flujo sanguíneo capilar ${ }^{96}$. En otras situaciones, para interpretar correctamente los acontecimientos metabólicos que tienen lugar en el encéfalo se requiere la cuantificación simultánea de varios metabolitos ${ }^{96}$.

En el encéfalo, el lactato intersticial surge como un metabolito intermedio en la glucólisis aerobia y se genera en grandes cantidades en la glucólisis anaerobia, en un intento de incrementar la producción de ATP a través de una ruta metabólica menos rentable. Por ello, cuando se objetivan niveles elevados de lactato en el encéfalo, éste puede proceder de un incremento del metabolismo aerobio (situación de hipermetabolismo celular), o de una situación de hipoxia tisular, isquémica o no isquémica, en la que la glucólisis es fundamentalmente anaerobia. El diagnóstico diferencial entre estas situaciones, conceptualmente opuestas, puede realizarse con la determinación simultánea de piruvato y el cálculo del índice lactato/piruvato ${ }^{38,77,83,103}$. Un incremento de lactato paralelo a un incremento de piruvato, con un índice lactato/piruvato normal, indican una situación de hipermetabolismo celular (Fig. 14). En cambio, un incremento de lactato acompañado de un descenso en el piruvato y un aumento del índice lactato piruvato son indicadores de isquemia tisular ${ }^{96}$.

El glicerol es uno de los componentes estructurales de la bicapa lipídica de la membrana celular. Situado en la parte más externa de la membrana celular (porción hidró- 


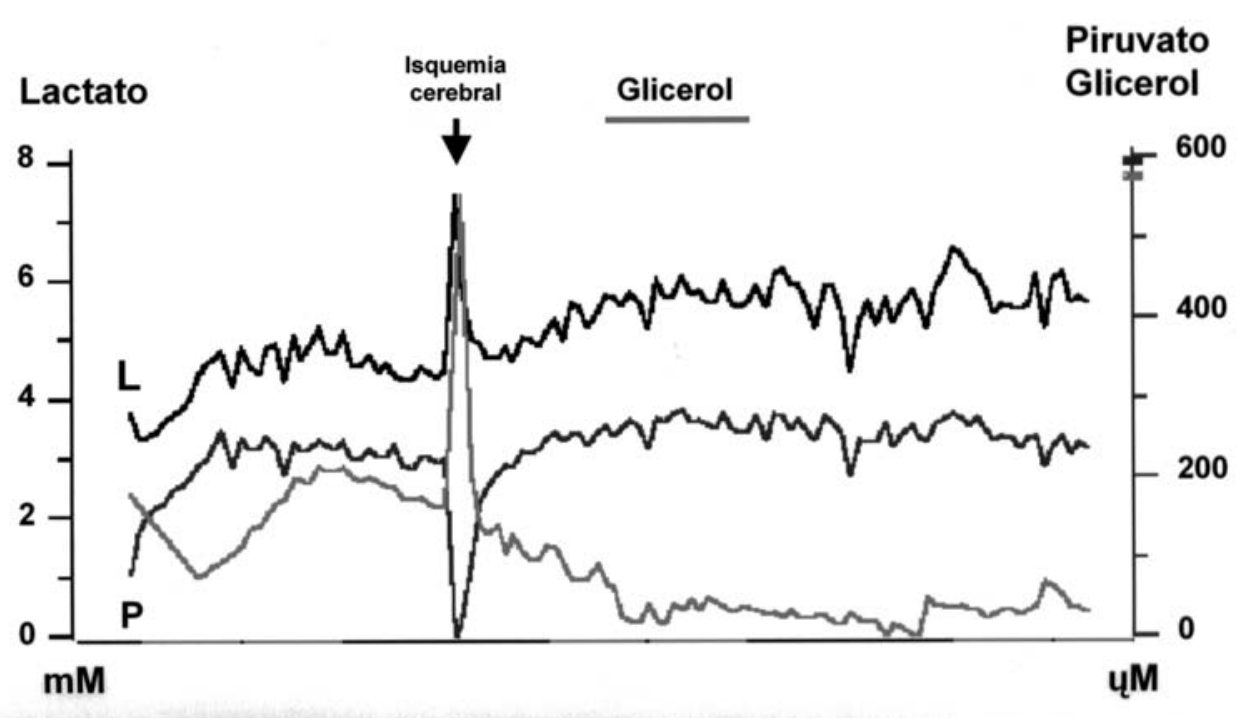

PIC

Glicerol

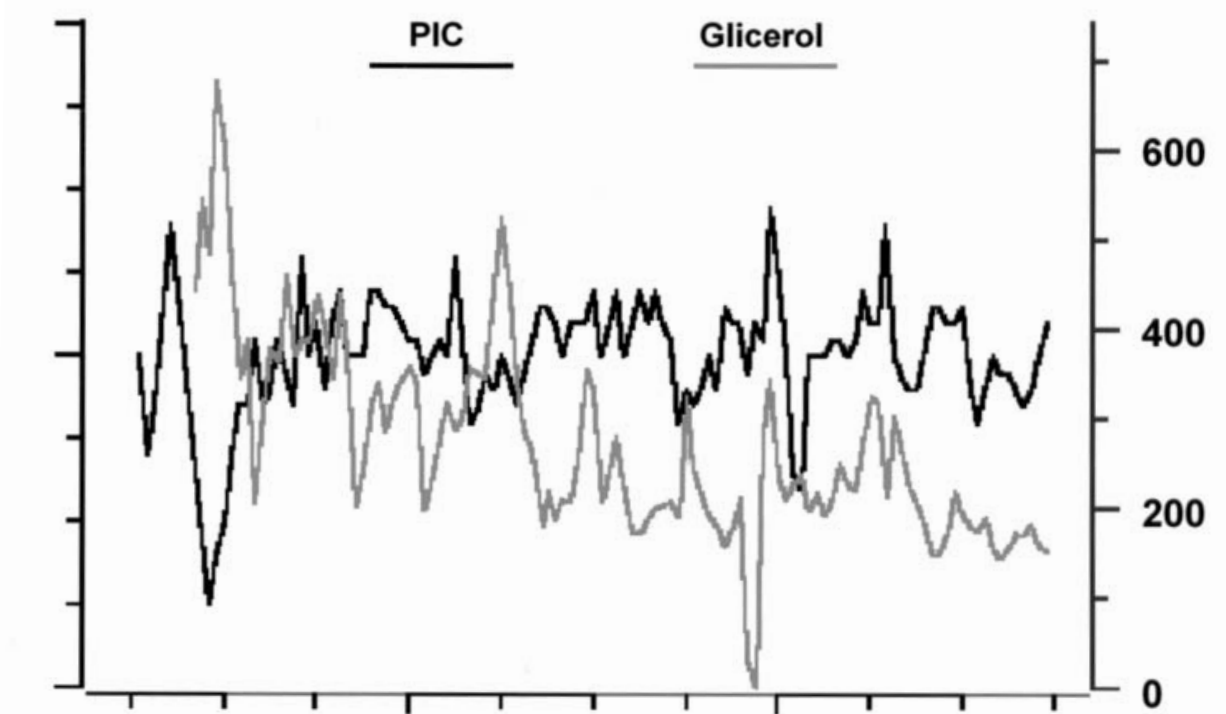

Figura 14. Esquema bioquímico de una situación de hipermetabolismo cerebral. La figura muestra cómo los valores de lactato y de piruvato aumentan de forma paralela, por lo que no se modifica índice lactato/piruvato. La figura también muestra un episodio de isquemia cerebral puntual (flecha) en la que existe un aumento del lactato con disminución del piruvato y aumento del glicerol.

Figura 15. Incrementos secuenciales de glicerol que coinciden con aumentos de la presión intracraneal (PIC). A pesar de que los valores de PIC no eran muy elevados, el paciente requería múltiples maniobras terapéuticas para mantener estos valores de PIC. Las elevaciones paralelas de ambos parámetros sugieren una situación de "stress" tisular.

\section{$\mathrm{mm} \mathrm{Hg}$}

fila), el glicerol se desprende de esta estructura en situaciones de falta de energía celular, constituyendo un marcador bioquímico de lesión tisular ${ }^{39,60,72}$. En situaciones de excitotoxicidad, mediadas por liberaciones masivas de glutamato en la hendidura sináptica, o en situación de falta de energía, se producen entradas incontroladas de calcio al interior de la célula. El calcio intracelular activa ciertas fosfolipasas y genera la formación de radicales libres de $\mathrm{O}_{2}$, que son los responsables de los fenómenos de peroxidación lipídica. La peroxidación lipídica desestructura de la membrana celular, con la consiguiente liberación de ácidos grasos y glicerol. En la práctica clínica, existen diversas situaciones que pueden generar "sufrimiento" celular. La figura 15 muestra cómo en un paciente aumentos moderados de la

\section{$4 \mathrm{M}$}

PIC provocaban incrementos de glicerol. En otro ejemplo podemos observar cómo la aplicación de medidas terapéuticas reduce los niveles de glicerol (Fig. 16).

Sin embargo, y a pesar de los hallazgos anteriores, en el momento actual no está claramente establecido si el aumento de glicerol se asocia a una destrucción de la membrana celular, con muerte secundaria de la célula, o sí bien constituye un marcador de "sufrimiento" celular, con posibilidad de reversión del proceso, sin que se produzca la destrucción de la célula. Por otra parte, estudios recientes han objetivado que maniobras tan simples y rutinarias como la aplicación de un enema de glicerol en un paciente puede incrementar de forma muy importante las concentraciones de esta sustancia ${ }^{27}$, lo que puede cuestionar su validez como 


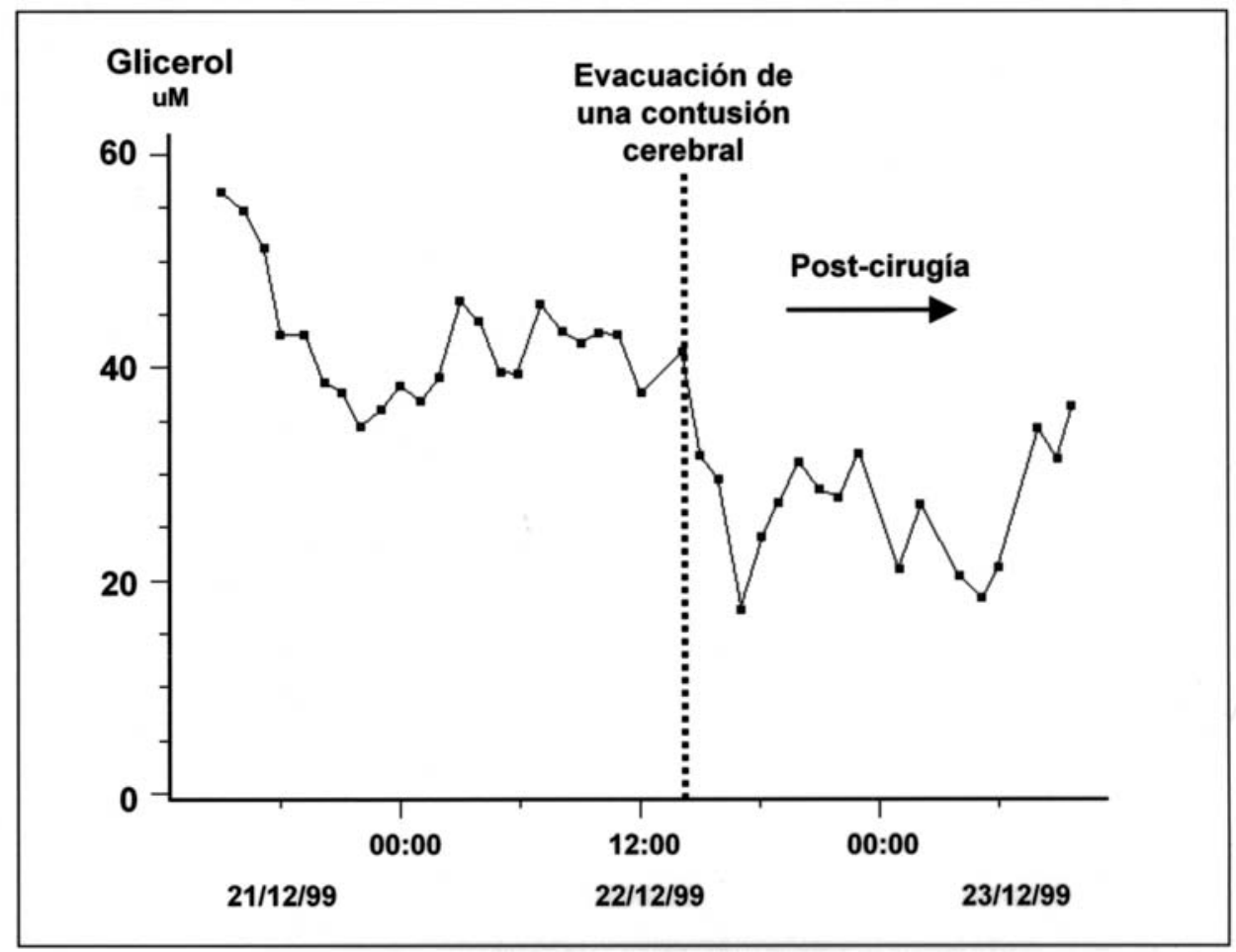

Figura 16. Reducción del glicerol después de la evacuación quirúrgica de una contusión cerebral, con el consiguiente descenso de la PIC. elemento marcador de lesión tisular.

El glutamato es el neurotransmisor excitatorio más abundante en el sistema nervioso de los mamíferos, seguido en importancia del aspartato. El glutamato se distribuye prácticamente por todas las regiones encefálicas y su acción es indispensable en la transmisión neuronal norma ${ }^{46}$. Cuando la neurona se despolariza, el glutamato se libera en la hendidura sináptica ejerciendo su acción sobre un conjunto variable de receptores. La función de este neurotransmisor depende fundamentalmente del tipo de receptor sobre el que actúe $e^{32,45}$.

En los TCE graves existen determinadas situaciones (hipoxia, isquemia, lesión mecánica con ruptura de membranas celulares, liberación de contenido hemático, etc.), en las que se liberan grandes cantidades de glutamato y aspartato al espacio extracelular. En estas circunstancias, ambos neurotransmisores, pero especialmente el glutamato, pueden ejercer una acción excitadora repetida e incontrolada sobre las neuronas, llevándolas a un estado de despolarización repetitivo que puede condicionar la auto-destrucción celular (fenómeno de excitotoxicidad) ${ }^{19,53,54,71}$. Dado que los fenómenos isquémicos provocan una liberación masiva de estos neurotransmisores, su determinación también puede utilizarse como un marcador de lesión tisular.

Ventajas de incluir la urea entre los metabolitos a analizar en la cabecera del paciente

Como en cualquier técnica de alta precisión y en la que se basan decisiones clínicas, en la microdiálisis es fundamental disponer de algún sistema capaz de identificar valores artefactuales que pueden estar incluídos entre los valores válidos. Ronne-Engstrom et al. ${ }^{78}$ propusieron el uso de la urea para detectar problemas en el funcionamiento de los catéteres de microdiálisis, ya que esta molécula actúa como compuesto endógeno de referencia. Un compuesto endógeno de referencia es una sustancia presente de forma natural en el organismo, que una vez sintetizada no se metaboliza y es capaz de difundir libremente a través de las membranas biológicas, alcanzando una concentración similar y estable en todos los fluidos sistémicos. La urea es una molécula de bajo peso molecular (60 Da) y de estructura polar, pero sin carga eléctrica, características que la hacen idónea para ser utilizada como un compuesto endógeno de referencia ${ }^{8,21,90}$, siempre que exista un periodo de tiempo suficiente para permitir una distribución homogénea de la molécula ${ }^{7,73}$.

En los mamíferos, la urea es el producto final principal del catabolismo del nitrógeno. La práctica totalidad de la urea presente en sangre y orina se sintetiza en el hígado y se excreta a través del riñón ${ }^{2}$, sin que su concentración presente oscilaciones bruscas. Asumiendo que la concentración de urea es similar en el líquido del espacio extracelular de cerebro y del tejido subcutáneo, el ratio entre la urea cerebral y la urea subcutánea de las muestras de microdiálisis constituye un buen control de calidad en la aplicación de esta técnica.

El ratio entre la urea cerebral y subcutánea suele oscilar 
TABLA 2

Valores normales y patológicos de diversos metabolitos en el espacio intersticial cerebral*

\begin{tabular}{lcccccc}
\hline \multicolumn{1}{c}{$\mathbf{n = 9}$} & $\begin{array}{c}\text { Glucosa } \\
(\mathbf{m m o l} / \mathbf{L})\end{array}$ & $\begin{array}{c}\text { Lactato } \\
(\mathbf{m m o l} / \mathbf{L})\end{array}$ & $\begin{array}{l}\text { Piruvato } \\
(\mu \mathbf{m o l} / \mathbf{L})\end{array}$ & Indice $\mathbf{L} / \mathbf{P}$ & $\begin{array}{l}\text { Glicerol } \\
(\mu \mathrm{mol} / \mathbf{L})\end{array}$ & $\begin{array}{l}\text { Glutamato } \\
(\mu \mathrm{mol} / \mathbf{L})\end{array}$ \\
$\begin{array}{l}\text { Paciente anestesiado } \\
(1,0 \mu \mathrm{L} / \mathrm{min})\end{array}$ & $1,2 \pm 0,6$ & $1,2 \pm 0,6$ & $70 \pm 24$ & $22 \pm 6$ & $28 \pm 16$ & $17 \pm 12$ \\
$\begin{array}{l}\text { Paciente despierto } \\
(1,0 \mu \mathrm{L} / \mathrm{min})\end{array}$ & $0,9 \pm 0,6$ & $1,4 \pm 0,9$ & $103 \pm 50$ & $21 \pm 6$ & $42 \pm 29$ & $7 \pm 5$ \\
$\begin{array}{l}\text { Paciente despierto } \\
(0,3 \mu \mathrm{L} / \mathrm{min})\end{array}$ & $1,7 \pm 0,9$ & $2,9 \pm 0,9$ & $166 \pm 47$ & $23 \pm 4$ & $82 \pm 44$ & $16 \pm 16$ \\
\hline Isquemia cerebral & $0,1 \pm 0,2$ & $8,9 \pm 6,5$ & $31 \pm 46$ & $>23 \pm 4$ & $570 \pm 430$ & $380 \pm 240$ \\
\hline
\end{tabular}

* Tabla de valores normales obtenida a partir del estudio de Reinstrup y col. ${ }^{74}$. Los valores "normales" (filas en blanco) fueron obtenidos en la sustancia blanca normal, supratentorial, de 9 pacientes intervenidos de lesiones cerebelosas benignas (6 meningiomas, 2 neurinomas del acústico y 1 ependimoma). Indice L/P: Índice lactato / piruvato.

entre 0,5 y 1 en diferentes pacientes. Esta variabilidad se debe a las diferentes condiciones fisicoquímicas y fisiológicas que se dan en el tejido en el que está insertado cada catéter y que afectan directamente a la cantidad de urea recogida por cada uno de los catéteres ${ }^{4,5}$. Sin embargo, el valor del ratio urea cerebral/subcutánea medido entre una pareja de catéteres concretos debería ser constante en un paciente determinado. De este modo, si el ratio urea cerebral versus urea subcutánea es constante, se puede afirmar que los dos catéteres de microdiálisis están funcionando correctamente. Cuando el ratio es constante, las oscilaciones en la concentración de los otros analitos estudiados de forma simultánea serían un reflejo correcto de las oscilaciones reales de estos analitos en el espacio intersticial. Un aumento o disminución del ratio entre la urea cerebral y la urea subcutánea indicarán una disfunción de uno de los dos catéteres.

La urea no debe utilizarse como sustancia de referencia en casos de insuficiencia renal, puesto que en esta situación su concentración puede sufrir oscilaciones bruscas ${ }^{69,78}$.

\section{Valores de referencia/normalidad de los metabolitos cerebrales}

Uno de los problemas fundamentales de la microdiálisis radica en establecer los valores de normalidad de los diferentes metabolitos. Dada la imposibilidad ética y metodológica de monitorizar a individuos normales, los valores de referencia deben obtenerse a partir de pacientes con patología intracraneal, con las limitaciones que esto supone. En el último simposium mundial sobre monitorización neuroquímica cerebral, celebrado en Cambridge (julio de 2000), se presentaron los primeros resultados de la monitorización con microdiálisis en un grupo de nueve pacientes que habían sido intervenidos de un proceso expansivo intracraneal. Seis de los nueve pacientes presentaban un meningioma; dos pacientes presentaban un neurinoma del acústico y el paciente restante presentaba un ependimoma. En todos los casos el catéter de microdiálisis se implantó en tejido sano. Posteriormente este estudio se publicó de forma más extensa en Neurosurgery ${ }^{74}$. La Tabla 2 resume los resultados de estos estudios e indica los umbrales de isquemia de diversos metabolitos cerebrales.

\section{¿Dónde debe colocarse el catéter de microdiálisis cere- bral? Técnicas de implantación}

Al igual que en otros sistemas de monitorización locales, en la microdiálisis cerebral surge el dilema de donde debe implantarse el catéter para obtener la información más útil para el manejo clínico del enfermo. La implantación de un catéter en el tejido "sano" ofrece la posibilidad de monitorizar el tejido con mayores posibilidades de recuperación. Por otro lado, la colocación de un catéter en las áreas de "penumbra", considerando como tales las zonas adyacentes a las lesiones focales, permiten el seguimiento de regiones cerebrales potencialmente recuperables. Para resolver este conflicto, y de forma ideal, en las lesiones focales deberían implantarse dos catéteres de microdiálisis en el parénquima encefálico, uno en el tejido sano y el segundo en el área de penumbra. En cambio, en las lesiones difusas es suficiente la colocación de un único catéter cerebral. En nuestros pacientes hemos constatado que en las lesiones focales la información que aportan dos catéteres cerebrales puede ser muy distinta, confirmando la complejidad fisiopatológica de las lesiones neurotraumáticas (Fig. 17).

Para la colocación en el cerebro de los catéteres 

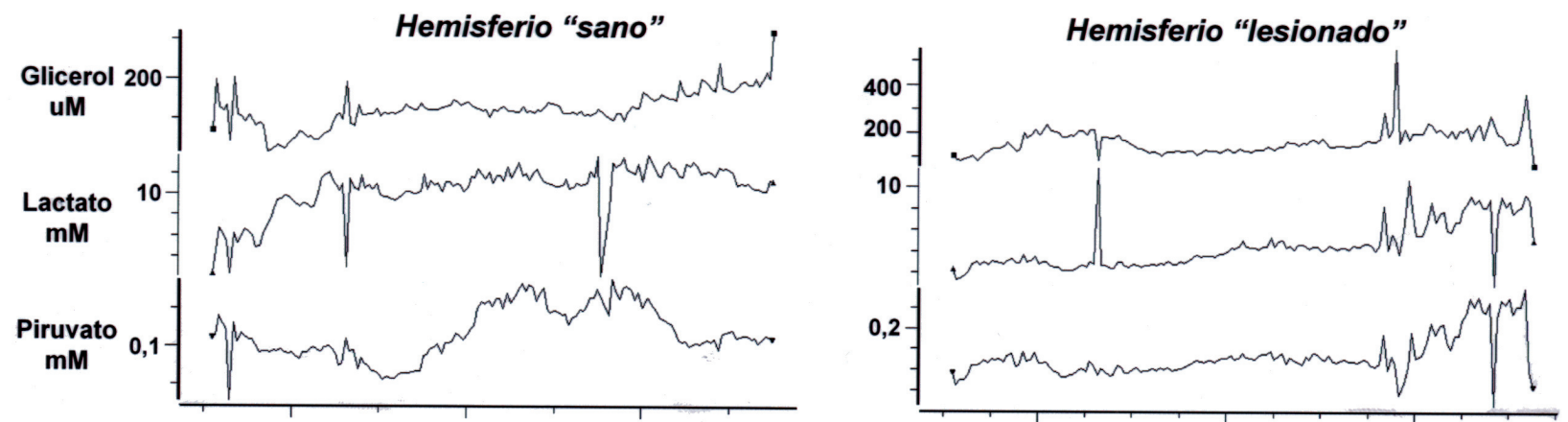

Figura 17. Valores de lactato, piruvato y glicerol obtenidos de forma simultánea en dos catéteres de microdiálisis cerebral implantados en un paciente afecto de un TCE grave (lesión difusa tipo II de la clasificación del TCDB). La imagen de la izquierda corresponde al hemisferio aparentemente menos lesionado y la de la derecha muestra los valores de una área de penumbra en el hemisferio cerebral contralateral. Puede observarse que los valores son muy diferentes en los dos hemisferios cerebrales.

de microdiálisis, inicialmente se utilizaron técnicas de estereotaxia. Sin embargo, estas técnicas, que pueden ser ideales en ciertos estudios experimentales, constituyen una importante limitación en el contexto clínico de los pacientes neurotraumáticos. En el momento actual en la mayoría de centros el catéter cerebral se implanta en quirófano, a través de un orificio de trépano con apertura de la duramadre e introducción del catéter bajo visión directa. Con el objetivo de facilitar la colocación del o de los catéteres cerebrales, en nuestro centro utilizamos una técnica percutánea, muy similar a la que se realiza para la colocación de un sensor de PIC intraparenquimatoso. Este sistema permite implantar los catéteres de microdiálisis en la propia UCI, al igual que el resto de sistemas de monitorización que se implantan en el paciente neurocrítico.

\section{Controles radiológicos. ¿Dónde se encuentra ubicada la membrana dializante?}

Un aspecto esencial en este tipo de monitorización es conocer la situación exacta del catéter de microdiálisis (sustancia gris, sustancia blanca, territorio cerebral específico, etc.). Hasta hace poco tiempo, los catéteres de microdiálisis no eran radio-opacos ni estaban dotados de marcadores radiológicos, por lo que era imposible determinar la posición exacta del catéter. Como dificultad adicional, si pretendíamos ubicar la membrana dializante en una posición cortical, la flexibilidad y el pequeño calibre de los catéteres favorecían su migración hacia el espacio subaracnoideo. En una etapa inicial, en nuestros pacientes resolvimos esta cuestión con la inyección de un pequeño volumen de aire introducido a través de la propia bomba de infusión. Al finalizar los 5 días de monitorización, y antes de retirar la bomba, se sustituía la solución de la jeringa por aire y se inyectaba una pequeña cantidad a través del catéter. Al cabo de unas 3 o 4 horas, se practicaba una TC cerebral de control en la que se apreciaba el trayecto intracerebral del catéter, permitiendo conocer la situación exacta de su extremo distal (Fig. 18). Esta maniobra se utiliza en otras técnicas neuroquirúrgicas y no ha supuesto ninguna complicación en los pacientes estudiados.

Desde hace poco tiempo disponemos de una nueva generación de catéteres de microdiálisis cerebral que incorporan una minúscula pieza de oro en su extremo distal, que resulta perfectamente visible en los controles radiológicos (Fig. 19).

\section{Limitaciones y complicaciones de la microdiálisis cerebral}

Entre las limitaciones de la microdiálisis cerebral debe citarse el hecho ya conocido de que se trata de un sistema de monitorización local, que puede no detectar acontecimientos metabólicos que tengan lugar en puntos alejados de la localización del catéter. Además, en función de la duración de la monitorización, se han descrito fenómenos de inflamación local que pueden dificultar el paso de moléculas desde el espacio intersticial al catéter de microdiálisis ${ }^{5}$. No obstante, se ha confirmado que este fenómeno no tiene ninguna relevancia clínica durante la primera semana de monitorización ${ }^{5,101}$. Otra limitación de la técnica es el tipo de moléculas que pueden determinarse a partir de la utilización de los catéteres con membranas dializantes de $20 \mathrm{KDa}$. Sin embargo, esta limitación ha quedado en gran parte resuelta, ya que acaban de introducirse en el mercado nuevos catéteres cerebrales dotados de membranas dializantes con poros de $100 \mathrm{KDa}$. Los nuevos catéteres permitirán determinar otras moléculas de mayor tamaño relacionadas con fenómenos de neuroinflamación y otros procesos que intervienen en la fisiopatología de ciertas lesiones neurológicas agudas. 


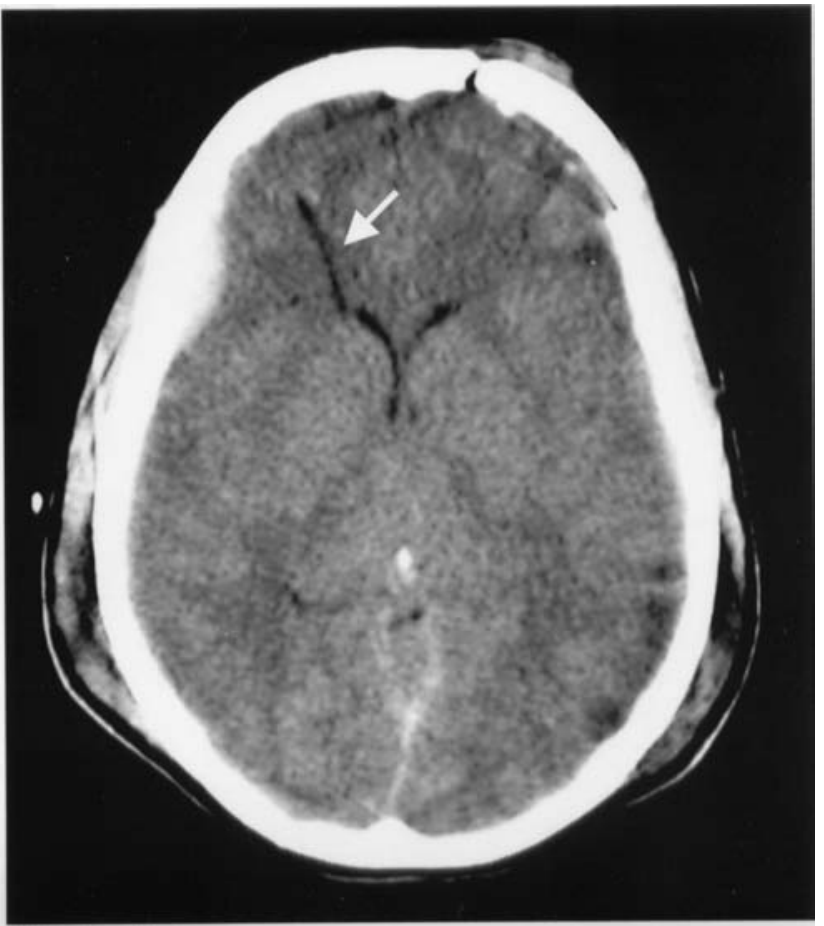

Figura 18. Control radiológico de la situación intracerebral del catéter de microdiálisis. La imagen aérea (flecha blanca) se consigue de forma retrospectiva al finalizar la monitorización. Después del $5^{\circ}$ día de estudio, se sustituye la solución dializante de la jeringa de infusión por aire cargado a través de un filtro bacteriano. La infusión de aire se prolonga durante unas 3 - 4 horas a un ritmo de infusión de $5 \mu \mathrm{L} / \mathrm{min}$. La TC cerebral de control debe realizarse de forma inmediata.

El índice de complicaciones atribuido a este sistema de monitorización en las diferentes series publicadas ha sido muy inferior al que se asocia a la colocación de un sensor de PIC. Los catéteres de microdiálisis cerebral son extremadamente finos $(0,62 \mathrm{~mm})$, lo que reduce al mínimo la posibilidad de lesión cerebral. No se han descrito complicaciones hemorrágicas significativas ni infecciones atribuibles a la microdiálisis cerebral ${ }^{66,82,87}$, probablemente porque se trata de un circuito que no se manipula (a excepción del intercambio de microviales) durante el tiempo que dura la monitorización. Las fracturas del catéter o de la membrana de microdiálisis se deben casi siempre a una mala manipulación del sistema y disminuyen al finalizar la curva de aprendizaje de cada centro.

A pesar de sus potenciales limitaciones, debemos afirmar que la microdiálisis cerebral es una técnica extremadamente sensible que puede aportar una información metabólica precoz sobre el establecimiento de una lesión tisular (Fig. 20). Esta técnica aporta una información muy superior a cualquier otro sistema de monitorización. A pesar

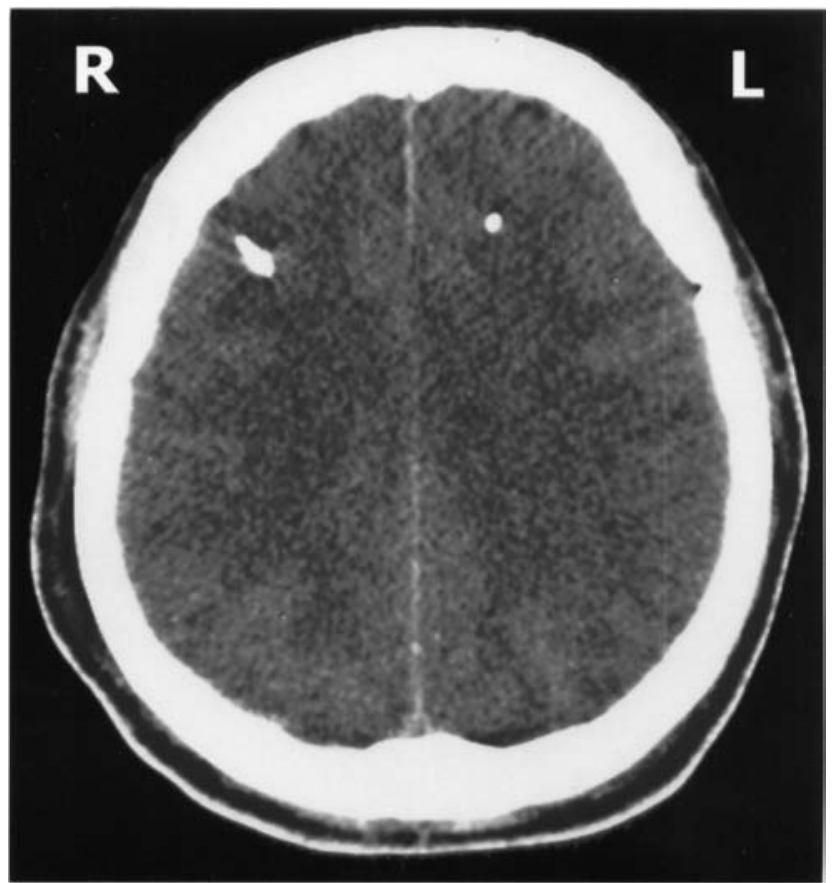

Figura 19. Imagen de TC cerebral de un paciente con un TCE grave portador de un doble catéter cerebral. En el hemisferio derecho $(R)$ se aprecia el artefacto radiológico del sensor de PtiO . En el hemisferio izquierdo (L) aparece el artefacto del elemento de oro incorporado en el catéter de microdiálisis.

de su innegable posición actual en el ámbito de la investigación, con toda probabilidad, su uso va a generalizarse en los próximos años, aportando nuevos conocimientos que permitan profundizar en la fisiopatología de los pacientes neurocríticos, así como optimizar su tratamiento.

\section{MONITORIZACIÓN NO INVASIVA DE LA OXIGENACIÓN CEREBRAL}

Además de los sistemas de neuromonitorización que se han comentado en los apartados anteriores, en los últimos años también se han introducido sistemas no invasivos, como el Doppler transcraneal y la espectroscopía por infrarrojos, que permiten realizar estimaciones secuenciales del FSC. Todas estas nuevas técnicas, con sus ventajas e inconvenientes, van siendo incorporadas de forma paulatina como sistemas de monitorización complementarios en el manejo diario de los pacientes neurocríticos.

\section{Espectroscopía por infrarrojos (near-infrared spectros- copy)}

Una de las propiedades de la luz infrarroja (650-1100 $\mathrm{nm}$ de longitud de onda) es que es capaz de penetrar 


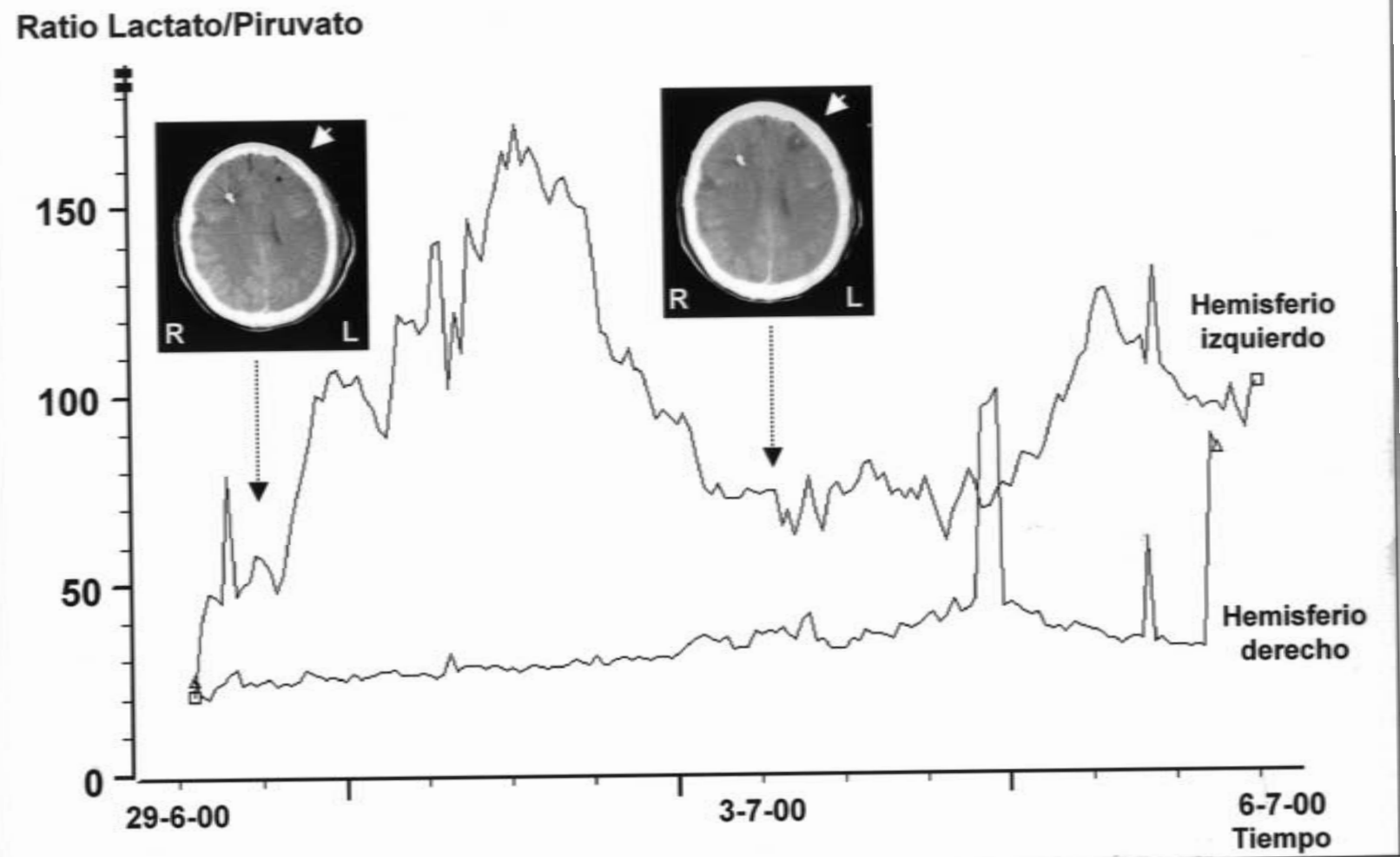

Figura 20. Evolución bioquímica de un infarto cerebral detectado por microdiálisis. Las alteraciones bioquímicas (aumento del lactato y del indice lactato/piruvato) aparecieron varios días antes de la imagen radiológica, confirmando la capacidad de información precoz de esta técnica de monitorización. La aparición de la hipodensidad radiológica explica los valores que se obtenían a partir del catéter de microdiálisis del hemisferio aparentemente "sano". Las flechas blancas señalan la imagen aérea que indica la situación del catéter de microdiálisis y, en la segunda TC, la cuña hipodensa que apareció en la zona en la que se alojaba este catéter de microdiálisis.

varios centímetros en los tejidos humanos. A su paso, esta luz es absorbida por moléculas "cromóforas" como la oxihemoglobina, la deoxihemoglobina y el citocromo$\mathrm{C}$ oxidasa. A partir de una emisión inicial de fotones, un fotodetector analiza la señal luminosa reflejada y cuantifica la luz que ha sido reabsorbida, lo que permite determinar la concentración de determinados cromóforos que contiene un tejido o una muestra biológica.

Las técnicas de espectroscopía óptica por infrarrojos se utilizaron inicialmente para realizar determinaciones bioquímicas. En el ámbito clínico, esta técnica está ampliamente difundida en el uso de la pulsioximetría periférica. En 1977, Jobsis introdujo la aplicación de este sistema al estudio del encéfalo ${ }^{43}$. No obstante, para poder cuantificar la concentración de oxihemoglobina cerebral, debía solucionarse el artefacto que suponía la absorción de luz infrarroja por parte del cuero cabelludo y de la calota craneal. Esto se consiguió con el uso simultáneo de 2 fotodetectores, situados a diferente distancia de la fuente de luz. El detector más cercano a la fuente luminosa detecta los fotones que provienen de los tejidos superficiales (cuero cabelludo y calota), mientras que el detector más alejado recibe la información global (parénquima encefálico, calota y cuero cabelludo) ${ }^{63}$. Una simple sustracción permite obtener la medición puramente cerebral.

En cada unidad de volumen de tejido encefálico, el 70$80 \%$ del contenido hemático se localiza en el lecho venoso, por lo que las técnicas de oximetría por espectroscopía ofrecen información esencialmente del contenido del compartimento venoso del cerebro. Las ventajas de la aplicación de este sistema transcutáneo en la monitorización de la hemodinámica cerebral son evidentes. Se trata de un sistema simple y no invasivo, que puede ofrecernos información continua sobre la oximetría cerebral regional. Sin embargo, a pesar de que la Food and Drug Administration aprobó el uso clínico de este tipo de monitores, en el momento actual todavía existen reticencias para utilizar este sistema de monitorización de forma exclusiva en las 
estimaciones del FSC en los pacientes neurocríticos ${ }^{20,33,52}$.

Diversos autores han comparado la información que se obtiene a partir de la espectroscopía por infrarrojos con los valores de $\mathrm{SjO}_{2}$ y $\mathrm{PtiO}_{2}$ en diferentes situaciones patológicas o durante la administración de diversas medidas terapéuticas (inducción de hiperventilación, administración de manitol...). El resultado general es que no existe una buena correlación entre los diferentes parámetros monitorizados, aunque sí que suelen existir las mismas tendencias en sus cambios ${ }^{1,62,64,91}$. No obstante, al analizar estos estudios es importante que recordemos que la espectroscopía por infrarrojos ofrece una información regional, mientras que la $\mathrm{SjO}_{2}$ ofrece una información global y la $\mathrm{PtiO}_{2}$ una información estrictamente local. Además, los pacientes con un TCE pueden presentar un FSC heterogéneo, especialmente si presentan lesiones cerebrales focales, por lo que valores aparentemente discordes entre diferentes variables monitorizadas pueden simplemente expresar una realidad fisiopatológica difícil de interpretar.

Más que la comparabilidad de diversas variables, el aspecto más preocupante en relación a las técnicas de espectroscopía por infrarrojos aplicadas a la monitorización del encéfalo, es la validez en sí de la información que aportan. Diversos autores han aplicado una monitorización de la oximetría cerebral regional en pacientes en muerte cerebral (sistema INVOS 3100, Somanetics Corp.) y han objetivado que el monitor ofrecía lecturas que podrían considerarse incluso normales ${ }^{28,84}$. Los hallazgos más espectaculares corresponden a un estudio de Schwarz y col. en el que los valores medios de oximetría cerebral de los individuos en muerte cerebral fueron de $51,0 \pm 26,8 \%$, sólo algo por debajo de los valores obtenidos en un grupo control de voluntarios sanos $(68,4 \pm 5,2 \%)^{84}$. Además, estos autores demostraron que al extraer el encéfalo durante el estudio necrópsico, en 6 de los 18 casos estudiados los valores de la oximetría "cerebral" seguían siendo superiores al 60\% ${ }^{84}$. Estos resultados, que aparentemente invalidan totalmente este sistema de monitorización, han sido justificados por Nemoto y col. al afirmar que en situaciones de muerte cerebral y, por tanto, ausencia de metabolismo celular, existe un secuestro de contenido hemático en los capilares y en el lecho venoso que explicaría las lecturas positivas de las técnicas de espectroscopía por infrarrojos ${ }^{70}$.

En contraposición a estos resultados tan negativos, otros autores han objetivado que la espectroscopía por infrarrojos ofrece información útil sobre cambios de los valores de oximetría regional frente a maniobras terapéuticas o en el contexto de la aparición de nuevas lesiones cerebrales $^{29,30,75,76}$. Robertson y col. realizaron diversos estudios en los que confirmaron que, en presencia de hematomas cerebrales unilaterales (epidurales, subdurales y, en menor medida, intraparenquimatosos), existía una asimetría en la absorción de la luz de una longitud de onda de $760 \mathrm{~nm}$ entre ambos hemisferios cerebrales ${ }^{75,76}$. Esta asimetría desaparecía después de la reabsorción espontánea del hematoma o después de su evacuación quirúrgica. Del mismo modo, la asimetría en la absorción de luz infrarroja volvía a ser evidente en los casos de recidivas posquirúrgicas o en la aparición de hematomas diferidos, anticipándose incluso al aumento de la presión intracraneal ${ }^{75,76}$.

En la "evolución técnica" del sistema INVOS 3100, han aparecido modelos más recientes (INVOS 3100A, 4100,5100 ) cuyo objetivo básico es conseguir una información cerebral más "pura", en la que se discrimine con mayor efectividad la contaminación que procede de la piel, calota craneal y LCR subaracnoideo. Los nuevos equipos incluyen algoritmos cada vez más complejos que contemplan factores de corrección para la hemodilución, temperatura, tensión arterial, etc. ${ }^{11}$. La última generación de estos sistemas de monitorización (NIRO 500, Hamamatsu Photonincs, Corp., Hamamatsu, Japón) utiliza cuatro señales ópticas de diferente longitud de onda $(775,825$, 850 y $904 \mathrm{~nm}$ ), con las que es capaz de distinguir las diferentes moléculas cromóforas y cuantificar el porcentaje de oxihemoglobina $^{11}$. Sin embargo, el sistema NIRO 500 no discrimina la contaminación procedente de las cubiertas craneales $^{11}$.

Existen muchas posibilidades de que en un futuro próximo el continuo desarrollo de estos sistemas de monitorización no invasivos aporten una información fiable y clínicamente válida que permita sustituir a otros sistemas de monitorización más invasivos que en el momento actual se aplican a los pacientes neurocríticos.

\section{Agradecimientos}

Reconocemos y agradecemos la eficaz colaboración del personal de enfermería de la UCI de Traumatología en el registro de las numerosas variables que derivan de la monitorización multimodal aplicada a los pacientes neurotraumáticos.

Este trabajo ha sido financiado en parte por la beca FIS 03/0153 del Fondo de Investigación Sanitaria y por la Red Temática de Investigación Cooperativa de Enfermedades Neurológicas (Red CIEN, C3/06, Nodo 11, Hospital Universitario Vall d'Hebron ).

\section{Bibliografía}

1. Ali, M.S., Harmer, M., Vaughan, R.S., Dunne, J.A., Latto, I.P.: Spatially resolved spectroscopy (NIRO-300) does not agree with jugular bulb oxygen saturation in patients undergoing warm bypass surgery. Can J Anaesth 2001; 48: 497-501.

2. Bagnasco, S.M.: Urea: new questions about an ancient solute. J Nephrol 2000; 13: 260-266. 
3. Bardt, T.F., Unterberg, A.W., Hartl, R., Kiening, K.L., Schneider, G.H., Lanksch, W.R.: Monitoring of brain tissue PO2 in traumatic brain injury: effect of cerebral hypoxia on outcome. Acta Neurochir Suppl 1998; 71: 153-156.

4. Benveniste, H.: Brain microdialysis. J Neurochem 1989; 52: 1667-1679.

5. Benveniste, H., Diemer, N.H.: Cellular reactions to implantation of a microdialysis tube in the rat hippocampus. Acta Neuropathol 1987; 74: 234-238.

6. Bito, L., Davson, H., Levin, E., Murray, M., Snider, N.: The concentrations of free amino acids and other electrolytes in cerebrospinal fluid, in vivo dialysate of brain, and blood plasma of the dog. J Neurochem 1966; 13: 1057-1067.

7. Bradbury, M.W., Coxon, R.V.: The penetration of urea into the central nervous system at high blood levels. J Physiol 1962; 163: 423-435.

8. Brunner, M., Joukhadar, C., Schmid, R., Erovic, B., Eichler, H.G., Muller, M.: Validation of urea as an endogenous reference compound for the in vivo calibration of microdialysis probes. Life Sci 2000; 67: 977-984.

9. Bruzzone, P., Dionigi, R., Bellinzona, G., Imberti, R., Stocchetti, N.: Effects of cerebral perfusion pressure on brain tissue PO2 in patients with severe head injury. Acta Neurochir Suppl 1998; 71: 111-113.

10. Bullock, M.R.: Hyperoxia: good or bad? J Neurosurg 2003; 98: 943-944.

11. Cho, H., Nemoto, E.M., Sanders, M., Fernandez, K., Yonas, H.: Comparison of two commercially available nearinfrared spectroscopy instruments for cerebral oximetry. J Neurosurg 2000; 93: 351-354.

12. Delgado, J.M., DeFeudis, F.V., Roth, R.H., Ryugo, D.K., Mitruka, B.M.: Dialytrode for long term intracerebral perfusion in awake monkeys. Arch Int Pharmacodyn Ther 1972; 198: 9-21.

13. Dings, J., Meixensberger, J., Amschler, J., Hamelbeck, B., Roosen, K.: Brain tissue $\mathrm{pO}_{2}$ in relation to cerebral perfusion pressure, TCD findings and TCD- $\mathrm{CO}_{2}$-reactivity after severe head injury. Acta Neurochir 1996; 138: 425-434.

14. Dings, J., Meixensberger, J., Amschler, J., Roosen, K.: Continuous monitoring of brain tissue $\mathrm{PO}_{2}$ : a new tool to minimize the risk of ischemia caused by hyperventilation therapy. Zentralbl Neurochir 1996; 57: 177-183.

15. Dings, J., Meixensberger, J., Jager, A., Roosen, K.: Clinical experience with 118 brain tissue oxygen partial pressure catheter probes. Neurosurgery 1998; 43: 1082-1095.

16. Dings, J., Meixensberger, J., Roosen, K.: Brain tissue pO2-monitoring: catheter stability and complications. Neurol Res 1997; 19: 241-245.

17. Doppenberg, E.M., Zauner, A., Bullock, R., Ward, J.D., Fatouros, P.P., Young, H.F.: Correlations between brain tissue oxygen tension, carbon dioxide tension, $\mathrm{pH}$, and cerebral blood flow. A better way of monitoring the severely injured brain? Surg Neurol 1998; 49: 650-654.
18. Doppenberg, E.M., Zauner, A., Watson, J.C., Bullock, R.: Determination of the ischemic threshold for brain oxygen tension. Acta Neurochir Suppl 1998; 71: 166-169.

19. Duhaime, A.C.: Exciting your neurons to death: can we prevent cell loss after brain injury? Pediat Neurosurg 1994; 21: 117-122.

20. Dullenkopf, A., Frey, B., Baenziger, O., Gerber, A., Weiss, M.: Measurement of cerebral oxygenation state in anaesthetized children using the INVOS 5100 cerebral oximeter. Paediatr Anaesth 2003; 13: 384-391.

21. Eisenberg, E.J., Eickhoff, W.M.: A method for estimation of extracellular concentration of compounds by microdialysis using urea as an endogenous recovery marker in vitro validation. J Pharmacol Toxicol Methods 1993; 30: 27-31.

22. Fandino, J., Stocker, R., Prokop, S., Imhof, H.G.: Correlation between jugular bulb oxygen saturation and partial pressure of brain tissue oxygen during $\mathrm{CO}_{2}$ and $\mathrm{O}_{2}$ reactivity tests in severely head-injured patients. Acta Neurochir 1999; 141: 825-834.

23. Fleckenstein, W., Heinrich, R., Grauer, W., Schomerus, H., Dolle, W., Weiss, C.: Fast local regulations of muscle $\mathrm{pO}_{2}-$ fields in patients suffering from cirrhosis of the liver. Adv Exp Med Biol 1984; 180: 687-694.

24. Fleckenstein, W., Maas, A.I,R.: Continuous recordings of oxygen pressure in the cerebrospinal fluid of cat, dog and man. Funktionsanalyse Biologisher Systeme 1989; 19: 211224.

25. Fleckenstein, W., Weiss, C.: A comparison of $\mathrm{pO}_{2}$ histograms from rabbit hind-limb muscles obtained by simultaneous measurements with hypodermic needle electrodes and with surface electrodes. Adv Exp Med Biol 1984; 169: 447455.

26. Gaddum, J.H.: Push-pull cannulae. J Physiol 1961; 155: $1-2$.

27. Gliemroth, J., Klaus, S., Bahlmann, L., et al.: Interstitial glycerol increase in microdialysis after glycerol enema. $\mathrm{J}$ Clin Neurosci 2004; 11: 53-56.

28. Gomersall, C.D., Joynt, G.M., Gin, T., Freebairn, R.C., Stewart, I.E.: Failure of the INVOS 3100 cerebral oximeter to detect complete absence of cerebral blood flow. Crit Care Med 1997; 25: 1252-1254.

29. Gopinath, S.P., Robertson, C.S., Contant, C.F., Narayan, R.K., Grossman, R.G., Chance, B.: Early detection of delayed traumatic intracranial hematomas using near-infrared spectroscopy. J Neurosurg 1995; 83: 438-444.

30. Gopinath, S.P., Robertson, C.S., Grossman, R.G., Chance, B.: Near-infrared spectroscopic localization of intracranial hematomas. J Neurosurg 1993; 79: 43-47.

31. Gopinath, S.P., Valadka, A.B., Uzura, M., Robertson, C.S.: Comparison of jugular venous oxygen saturation and brain tissue $\mathrm{pO}_{2}$ as monitors of cerebral ischemia after head injury. Crit Care Med 1999; 27: 2337-2345.

32. Greenamyre, J.T., Porter, R.H.P.: Anatomy and physio- 
logy of glutamate in the CNS. Neurology 1994; 44: S7-S13.

33. Gupta, A.K.: Monitoring the injured brain in the intensive care unit. J Postgrad Med 2002; 48: 218-225.

34. Gupta, A.K., Hutchinson, P.J., Al Rawi, P., et al.: Measuring brain tissue oxygenation compared with jugular venous oxygen saturation for monitoring cerebral oxygenation after traumatic brain injury. Anesth Analg 1999; 88: 549-553.

35. Gupta, A.K., Hutchinson, P.J., Fryer, T., et al.: Measurement of brain tissue oxygenation performed using positron emission tomography scanning to validate a novel monitoring method. J Neurosurg 2002; 96: 263-268.

36. Haitsma, I.K., Maas, A.I.: Advanced monitoring in the intensive care unit: brain tissue oxygen tension. Curr Opin Crit Care 2002; 8: 115-120.

37. Hemphill, J.C., 3rd, Knudson, M.M., Derugin, N., Morabito, D., Manley, G.T.: Carbon dioxide reactivity and pressure autoregulation of brain tissue oxygen. Neurosurgery 2001; 48: 377-383.

38. Hillered, L., Persson, L., Ponten, U., Ungerstedt, U.: Neurometabolic monitoring of the ischaemic human brain using microdialysis. Acta Neurochir 1990; 102: 91-97.

39. Hillered, L., Valtysson, J., Enblad, P., Persson, L.: Interstitial glycerol as a marker for membrane phospholipid degradation in the acutely injured human brain. J Neurol Neurosurg Psychiatry 1998; 64: 486-491.

40. Hutchinson, P.J., O'Connell, M.T., Al Rawi, P.G., et al.: Clinical cerebral microdialysis: determining the true extracellular concentration. Acta Neurochir Suppl 2002; 81: 359-362.

41. Hutchinson, P.J., O'Connell, M.T., Al Rawi, P.G., et al.: Clinical cerebral microdialysis: a methodological study. J Neurosurg 2000; 93: 37-43.

42. Hutchinson, P.J., O'Connell, M.T., Kirkpatrick, P.J., Pickard, J.D.: How can we measure substrate, metabolite and neurotransmitter concentrations in the human brain? Physiol Meas 2002; 23: R75-109.

43. Jobsis, F.F.: Noninvasive, infrared monitoring of cerebral and myocardial oxygen sufficiency and circulatory parameters. Science 1977; 198: 1264-1267.

44. Johnston, A.J., Gupta, A.K.: Advanced monitoring in the neurology intensive care unit: microdialysis. Curr Opin Crit Care 2002; 8: 121-127.

45. Kalb, R.G.: Current excitement about the glutamate receptor family. The Neuroscientist 1995; 1: 60-63.

46. Kandel, E.R., Schwartz, J.H.: Directly gated transmission at central synapses. En Kandel ER, Schwartz JH, Jessell TM (eds). Principles of neural science. New York; Elsevier, 1991; pp. 53-172.

47. Kett-White, R., Hutchinson, P.J., Al Rawi, P.G., et al.: Cerebral oxygen and microdialysis monitoring during aneurysm surgery: effects of blood pressure, cerebrospinal fluid drainage, and temporary clipping on infarction. J Neurosurg 2002; 96: 1013-1019.
48. Kett-White, R., Hutchinson, P.J., Czosnyka, M., Boniface, S., Pickard, J.D., Kirkpatrick, P.J.: Multi-modal monitoring of acute brain injury. Adv Tech Stand Neurosurg 2002; 27: 87-134.

49. Kiening, K.L., Hartl, R., Unterberg, A.W., Schneider, G.H., Bardt, T., Lanksch, W.R.: Brain tissue $\mathrm{pO}_{2}$-monitoring in comatose patients: implications for therapy. Neurol Res 1997; 19: 233-240.

50. Kiening, K.L., Schneider, G.H., Bardt, T.F., Unterberg, A.W., Lanksch, W.R.: Bifrontal measurements of brain tissue$\mathrm{pO}_{2}$ in comatose patients. Acta Neurochir Suppl (Wien ) 1998; 71: $172-173$.

51. Kiening, K.L., Unterberg, A.W., Bardt, T.F., Schneider, G.H., Lanksch, W.R.: Monitoring of cerebral oxygenation in patients with severe head injuries: brain tissue $\mathrm{pO}_{2}$ versus jugular vein oxygen saturation. J Neurosurg 1996; 85: 751757.

52. Lewis, S.B., Myburgh, J.A., Thornton, E.L., Reilly, P.L.: Cerebral oxygenation monitoring by near-infrared spectroscopy is not clinically useful in patients with severe closedhead injury: a comparison with jugular venous bulb oximetry. Crit Care Med 1996; 24: 1334-1338.

53. Lipton, S.A.: Molecular mechanisms of trauma-induced neuronal degeneration. Curr Opin Neurol Neurosurg 1993; 6: 588-596.

54. Lipton, S.A., Rosenberg, P.A.: Mechanisms of disease. N Engl J Med 1994; 330: 613-622.

55. Littlejohns, L.R., Bader, M.K., March, K.: Brain tissue oxygen monitoring in severe brain injury, I. Research and usefulness in critical care. Crit Care Nurse 2003; 23: 17-25.

56. Maas, A.I., Fleckenstein, W., de Jong, D.A., van Santbrink, H.: Monitoring cerebral oxygenation: experimental studies and preliminary clinical results of continuous monitoring of cerebrospinal fluid and brain tissue oxygen tension. Acta Neurochir Suppl 1993; 59: 50-57.

57. Magnoni, S., Ghisoni, L., Locatelli, M., et al.: Lack of improvement in cerebral metabolism after hyperoxia in severe head injury: a microdialysis study. J Neurosurg 2003; 98: 952958 .

58. Manley, G.T., Hemphill, J.C., Morabito, D., et al.: Cerebral oxygenation during hemorrhagic shock: perils of hyperventilation and the therapeutic potential of hypoventilation. J Trauma 2000; 48: 1025-1032.

59. Manley, G.T., Pitts, L.H., Morabito, D., et al.: Brain tissue oxygenation during hemorrhagic shock, resuscitation, and alterations in ventilation. J Trauma 1999; 46: 261-267.

60. Marklund, N., Salci, K., Lewen, A., Hillered, L.: Glycerol as a marker for post-traumatic membrane phospholipid degradation in rat brain. Neuroreport 1997; 8: 1457-1461.

61. Martin, N.A., Patwardhan, R.V., Alexander, M.J., et al.: Characterization of cerebral hemodynamic phases following severe head trauma: Hypoperfusion, hyperemia, and vasospasm. J Neurosurg 1997; 87: 9-19. 
62. Mccormick, P.W., Stewart, M., Goetting, M.G., Balakrishnan, G.: Regional cerebrovascular oxygen saturation measured by optical spectroscopy in humans. Stroke 1991; 22: 596-602.

63. Mccormick, P.W., Stewart, M., Goetting, M.G., Dujovny, M., Lewis, G., Ausman, J.I.: Noninvasive cerebral optical spectroscopy for monitoring cerebral oxygen delivery and hemodynamics. Crit Care Med 1991; 19: 89-97.

64. McLeod, A.D., Igielman, F., Elwell, C., Cope, M., Smith, M.: Measuring cerebral oxygenation during normobaric hyperoxia: a comparison of tissue microprobes, near-infrared spectroscopy, and jugular venous oximetry in head injury. Anesth Analg 2003; 97: 851-856.

65. Meixensberger, J., Dings, J., Kuhnigk, H., Roosen, K.: Studies of tissue $\mathrm{PO}_{2}$ in normal and pathological human brain cortex. Acta Neurochir Suppl 1993; 59: 58-63.

66. Meixensberger, J., Kunze, E., Barcsay, E., Vaeth, A., Roosen, K.: Clinical cerebral microdialysis: brain metabolism and brain tissue oxygenation after acute brain injury. Neurol Res 2001; 23: 801-806.

67. Menzel, M., Doppenberg, E.M., Zauner, A., Soukup, J., Reinert, M.M., Bullock, R.: Increased inspired oxygen concentration as a factor in improved brain tissue oxygenation and tissue lactate levels after severe human head injury. J Neurosurg 1999; 91: 1-10.

68. Menzel, M., Doppenberg, E.M., Zauner, A, et al.: Cerebral oxygenation in patients after severe head injury: monitoring and effects of arterial hyperoxia on cerebral blood flow, metabolism and intracranial pressure. J Neurosurg Anesthesiol 1999; 11: 240-251.

69. Metry, G.S., Attman, P.O., Lonnroth, P., Beshara, S.N., Aurell, M.: Urea kinetics during hemodialysis measured by microdialysis: a novel technique. Kidney Int 1993; 44: 622629.

70. Nemoto, E.M., Yonas, H., Kassam, A.: Clinical experience with cerebral oximetry in stroke and cardiac arrest. Crit Care Med 2000; 28: 1052-1054.

71. Olney, J.W.: Neurotoxicity of NMDA receptor antagonists: an overview. Phychopharmacology Bulletin 1994; 30: 533-540.

72. Peerdeman, S.M., Girbes, A.R., Polderman, K.H., Vandertop, W.P.: Changes in cerebral interstitial glycerol concentration in head-injured patients; correlation with secondary events. Intensive Care Med 2003; 29: 1825-1828.

73. Rapoport, S.I., Fitzhugh, R., Pettigrew, K.D., Sundaram, U., Ohno, K.: Drug entry into and distribution within brain and cerebrospinal fluid: urea pharmacokinetics. Am J Physiol 1982; 242: R339-R348.

74. Reinstrup, P., Stahl, N., Mellergard, P., Uski, T., Ungerstedt, U., Nordstrom, C.H.: Intracerebral microdialysis in clinical practice: baseline values for chemical markers during wakefulness, anesthesia, and neurosurgery. Neurosurgery 2000; 47: 701-709.
75. Robertson, C.S., Gopinath, S.P., Chance, B.: A new application for near-infrared spectroscopy: detection of delayed intracranial hematomas after head injury. J Neurotrauma 1995; 12: 591-600.

76. Robertson, C.S., Gopinath, S.P., Chance, B.: Identifying intracranial hematomas with near-infrared spectroscopy. En Litscher G, Schwarz G, (eds). Transcranial Cerebral Oximetry. D-49525 Lengerich; Pabst Science Publis, 1997: pp. 131-141.

77. Robertson, C.S., Gopinath, S.P., Uzura, M., Valadka, A.B., Goodman, J.C.: Metabolic changes in the brain during transient ischemia measured with microdialysis. Neurol Res 1998; 20 Suppl 1: S91-S94.

78. Ronne-Engstrom, E., Cesarini, K.G., Enblad, P., et al.: Intracerebral microdialysis in neurointensive care: the use of urea as an endogenous reference compound. J Neurosurg 2001; 94: 397-402.

79. Sahuquillo, J., Amoros, S., Poca, M.A., et al.: Coexistence of regional cerebral hypoxia with normal or hyperemic brain detected by global monitoring methods. Analysis of apparently contradictory findings based on the SiggaardAndersen model of tissue hypoxia. Acta Neurochir Suppl 2002; 81: 303-305.

80. Sahuquillo, J., Amoros, S., Santos, A., et al.: Does an increase in cerebral perfusion pressure always mean a better oxygenated brain? A study in head-injured patients. Acta Neurochir Suppl 2000; 76: 457-462.

81. Sarrafzadeh, A.S., Kiening, K.L., Bardt, T.F., Schneider, G.H., Unterberg, A.W., Lanksch, W.R.: Cerebral oxygenation in contusioned vs. nonlesioned brain tissue: monitoring of $\mathrm{PtiO}_{2}$ with Licox and Paratrend. Acta Neurochir Suppl 1998; 71: 186-189.

82. Sarrafzadeh, A.S., Kiening, K.L., Callsen, T.A., Unterberg, A.W.: Metabolic changes during impending and manifest cerebral hypoxia in traumatic brain injury. Br J Neurosurg 2003; 17: 340-346.

83. Sarrafzadeh, A.S., Sakowitz, O.W., Lanksch, W.R., Unterberg, A.W.: Time course of various interstitial metabolites following subarachnoid hemorrhage studied by on-line microdialysis. Acta Neurochir Suppl 2001; 77: 145-147.

84. Schwarz, G., Litscher, G., Kleinert, R., Jobstmann, R.: Cerebral oximetry in dead subjects. J Neurosurg Anesthesiol 1996; 8: 189-193.

85. Siggaard-Andersen, M., Siggaard-Andersen, O.: Oxygen status algorithm, version 3, with some applications. Acta Anaesthesiol Scand Suppl 1995; 107: 13-20.

86. Siggaard-Andersen, O., Ulrich, A., Gothgen, I.H.: Classes of tissue hypoxia. Acta Anaesthesiol Scand Suppl 1995; 107: 137-142.

87. Skjoth-Rasmussen, J., Schulz, M., Kristensen, S.R., Bjerre, P.: Delayed neurological deficits detected by an ischemic pattern in the extracellular cerebral metabolites in patients with aneurysmal subarachnoid hemorrhage. J Neurosurg 
2004; 100: 8-15.

88. Stocchetti, N., Chieregato, A., De Marchi, M., Croci, M., Benti, R., Grimoldi, N.: High cerebral perfusion pressure improves low values of local brain tissue $\mathrm{O}_{2}$ tension $\left(\mathrm{PtiO}_{2}\right)$ in focal lesions. Acta Neurochir Suppl 1998; 71: 162-165.

89. Stocchetti, N., Paparella, A., Bridelli, F., Bacchi, M., Piazza, P., Zuccoli, P.: Cerebral venous oxygen saturation studied with bilateral samples in the internal jugular veins. Neurosurgery 1994; 34: 38-44.

90. Strindberg, L., Lonnroth, P.: Validation of an endogenous reference technique for the calibration of microdialysis catheters. Scand J Clin Lab Invest 2000; 60: 205-211.

91. Ter Minassian, A., Poirier, N., Pierrot, M., et al.: Correlation between cerebral oxygen saturation measured by near-infrared spectroscopy and jugular oxygen saturation in patients with severe closed head injury. Anesthesiology 1999; 91: 985-990.

92. Tsai, A.G., Johnson, P.C., Intaglietta, M.: Oxygen gradients in the microcirculation. Physiol Rev 2003; 83: 933963.

93. Ungerstedt, U.: Microdialysis: principles and applications for studies in animals and man. J Intern Med 1991; 230: 365-373.

94. Ungerstedt, U., et al: http://www.microdialysis.com/ Bibliography/clinbibny.htm. Último acceso: 11 setiembre de 2004.

95. Ungerstedt, U., Pycock, C.: Functional correlates of dopamine neurotransmission. Bull Schweiz Akad Med Wiss 1974; 30: 44-55.

96. Ungerstedt, U., Rostami, E.: Microdialysis in neurointensive care. Curr Pharm Des 2004; 10: 2145-2152.

97. Valadka, A.B., Gopinath, S.P., Contant, C.F., Uzura, M., Robertson, C.S.: Relationship of brain tissue PO2 to outcome after severe head injury. Crit Care Med 1998; 26: 1576-1581.

\section{Comentario al trabajo de revisión sobre Métodos globales de monitorización en los pacientes neurocríticos de M.A. Poca y cols.}

La patología neurocrítica por TCE constituye la principal causa de morbimortalidad en personas menores de 45 años. Esta alta mortalidad, asociada a unos costes sociales económicos y sanitarios elevados, conforman un gran problema de Salud Pública.

Se empieza a tener una mayor conciencia de la magnitud del problema en la década de los años noventa, poniéndose en marcha una serie de medidas preventivas y asistenciales, (publicación de guías de actuación), que si bien logran disminuir la mortalidad en términos absolutos, mantienen una alta morbilidad y un coste elevado.
98. van den Brink, W.A., Haitsma, I.K., Avezaat, C.J., Houtsmuller, A.B., Kros, J.M., Maas, A.I.: Brain parenchyma/ $\mathrm{pO}_{2}$ catheter interface: a histopathological study in the rat. $\mathrm{J}$ Neurotrauma 1998; 15: 813-824.

99. van den Brink, W.A., van Santbrink, H., Steyerberg, E.W., et al.: Brain oxygen tension in severe head injury. Neurosurgery 2000; 46: 868-876.

100. van Santbrink, H., Maas, A.I., Avezaat, C.J.: Continuous monitoring of partial pressure of brain tissue oxygen in patients with severe head injury. Neurosurgery 1996; 38: 21-31.

101. Whittle, I.R., Glasby, M., Lammie, A., Bell, H., Ungerstedt, U.: Neuropathological findings after intracerebral implantation of microdialysis catheters. Neuroreport 1998; 9: 2821-2825.

102. Zauner, A., Bullock, R., Di, X., Young, H.F.: Brain oxygen, $\mathrm{CO}_{2}, \mathrm{pH}$, and temperature monitoring: Evaluation in the feline brain. Neurosurgery 1995; 37: 1168-1176.

103. Zauner, A., Doppenberg, E.M., Woodward, J.J., Choi, S.C., Young, H.F., Bullock, R.: Continuous monitoring of cerebral substrate delivery and clearance: Initial experience in 24 patients with severe acute brain injuries. Neurosurgery 1997; 41: 1082-1091.

Poca, M.A.; Sahuquillo, J.; Mena, M.P.; Vilalta, A.; Riveiro, M.: Actualizaciones en los métodos de monitorización cerebral regional en los pacientes neurocríticos: presión tisular de oxígeno, microdiálisis cerebral y técnicas de espectroscopía por infrarrojos. Neurocirugía 2005; 16 : $385-410$.

Correspondencia postal: M.A. Poca. Servicio de Neurocirugía. Hospital Universitario Vall d'Hebron. Paseo Vall d'Hebron 119129. 08035, Barcelona.
Todos los estudios anatomopatológicos publicados demuestran una alta incidencia de lesión secundaria isquémica, con independencia de la ocasionada por los procesos de herniación. Estas lesiones, en su mayoría, no son detectadas durante la evolución clínica a pesar de los esfuerzos asistenciales de monitorización para su tratamiento precoz.

Aunque la respuesta fisiopatológica del SNC a la agresión es conocida, su patrón hemometabólico, cambiante por el tipo de lesión y el tiempo evolutivo, hacen que su 
monitorización sea extremadamente compleja.

De forma progresiva, y sorteando no pocos problemas, muchos de ellos de carácter económico-administrativo, las unidades de Neurocríticos están incorporando nuevos equipos y técnicas de monitorización que aportan una información más completa, precisa y precoz y que pueden evitar o disminuir la lesión secundaria y con ello, y en definitiva, mejorar el pronóstico de estos pacientes.

La Unidad de Pacientes Neurocríticos del Hospital Universitario Vall d'Hebron, constituye uno de los equipos de vanguardia en el tratamiento de pacientes neurocríticos, siendo pioneros en la incorporación y utilización de nuevas técnicas de neuromonitorización. Queda reflejado en este trabajo de revisión y actualización, la enorme inquietud que este equipo de profesionales tiene por compartir sus conocimientos y mejorar la asistencia de los pacientes.

Del trabajo en su conjunto y a modo de conclusiones podemos señalar:

1. Hace una revisión precisa de las características técnicas y de funcionamiento de cada uno de los aparatos y sistemas, poniendo especial énfasis en el grado de fiabilidad de los mismos.

2. Da una interpretación clínica precisa y hace una valoración de los resultados, señalando los posibles errores interpretativos y buscando las soluciones más coherentes en función de los conocimientos fisiopatológicos.

3. Señala las limitaciones de las distintas técnicas de monitorización, estableciendo el valor exacto que a cada una de ellas se debe dar.

4. Trabajo muy documentado con una amplia referencia bibliográfica.

A modo de resumen, la unidad de Pacientes Neurocríticos del Hospital Universitario Vail d'Hebron pone su experiencia asistencial a disposición de todos los servicios que se están iniciando en la utilización de estas nuevas técnicas de monitorización, lo que sin duda facilitará de manera importante su labor de aprendizaje.

R. Núñez

Unidad de Cuidados Intensivos Hospital Virgen de la Arrixaca

Murcia 